Check for updates

Cite this: J. Mater. Chem. A, 2021, 9, 21958

Received 1st July 2021

Accepted 3rd September 2021

DOI: 10.1039/d1ta05561e

rsc.li/materials-a

\section{Elucidating the formation and active state of Cu co- catalysts for photocatalytic hydrogen evolution $\dagger$}

\author{
Jasmin S. Schubert, ${ }^{a}$ Leila Kalantari, ${ }^{a}$ Andreas Lechner, ${ }^{a}$ Ariane Giesriegl, ${ }^{a}$ \\ Sreejith P. Nandan, ${ }^{a}$ Pablo Alaya, ${ }^{a}$ Shun Kashiwaya, ${ }^{b}$ Markus Sauer, (D) c \\ Annette Foelske, ${ }^{c}$ Johanna Rosen, ${ }^{\text {b }}$ Peter Blaha, ${ }^{a}$ Alexey Cherevan (D)*a \\ and Dominik Eder (1D*a
}

The design of active and selective co-catalysts constitutes one of the major challenges in developing heterogeneous photocatalysts for energy conversion applications. This work provides a comprehensive insight into thermally induced bottom-up generation and transformation of a series of promising $\mathrm{Cu}$ based co-catalysts. We demonstrate that the volcano-type HER profile as a function of calcination temperature is independent of the type of the $\mathrm{Cu}$ precursor but is affected by changes in oxidation state and location of the copper species. Supported by DFT modeling, our data suggest that low temperature $\left(<200{ }^{\circ} \mathrm{C}\right)$ treatments facilitate electronic communication between the $\mathrm{Cu}$ species and $\mathrm{TiO}_{2}$, which allows for a more efficient charge utilization and maximum HER rates. In contrast, higher temperatures $\left(>200^{\circ} \mathrm{C}\right.$ ) do not affect the $\mathrm{Cu}$ oxidation state, but induce a gradual, temperature-dependent surfaceto-bulk diffusion of $\mathrm{Cu}$, which results in interstitial, tetra-coordinated $\mathrm{Cu}^{+}$species. The disappearance of $\mathrm{Cu}$ from the surface and the introduction of new defect states is associated with a drop in HER performance. This work examines electronic and structural effects that are in control of the photocatalytic activity and can be transferred to other systems for further advancing photocatalysis.

\section{Introduction}

Photocatalysis can contribute to the development of environmentally-friendly processes relevant to water purification technologies, antibacterial applications, $\mathrm{CO}_{2}$ reduction as well as the energy sector..$^{\mathbf{1 - 4}}$ As such, photocatalytic water splitting towards light-driven hydrogen generation has the capability to be part of the solution to overcome the energy-related challenges of our times. To engineer the most efficient photocatalyst, heterogeneous photocatalysis has shown to be an advantageous approach, as it can combine a solid-state semiconductor - able to absorb light, generate electron-hole pairs and transfer their energy to the catalytic sites - and a co-catalyst with more suitable catalytic properties, which enables the desired oxidation and reduction half-reactions. ${ }^{2,3,5}$ Additionally, the co-catalysts can act as a driving force for quick separation of photoexcited charge carriers, by extracting the charge carriers

anstitute of Materials Chemistry, Technische Universität Wien (TU Wien), Getreidemarkt 9, 1060, Vienna, Austria. E-mail: alexey.cherevan@tuwien.ac.at; dominik.eder@tuwien.ac.at

${ }^{b}$ Materials Design, Department of Physics, Chemistry, and Biology (IFM), Linköping University, 58183, Linköping, Sweden

${ }^{c}$ Analytical Instrumentation Center, Technische Universität Wien (TU Wien), Lehargasse 6, 1060 Vienna, Austria

$\dagger$ Electronic supplementary information (ESI) available. See DOI: 10.1039/d1ta05561e from the bulk and preventing their recombination, leading ultimately to enhanced charge separation and photocatalytic activity. ${ }^{6}$ The use of tailor-made co-catalysts deposited on the photocatalyst surface thus, provides a means to control the catalytic sites to enhance and tune efficiency and adsorptiondesorption equilibria of the reaction of interest. ${ }^{6}$ Therefore, cocatalyst engineering has emerged as one of the most promising strategies to achieve high photocatalytic performance.

The light-to-hydrogen conversion efficiency of the final photocatalyst strongly depends on the electronic interaction and band alignments between the two components, as the photogenerated charge carries need to be effectively transferred between the semiconductor substrate and the catalytic sites. ${ }^{6}$ Besides, the accessibility of the co-catalyst to the reactants also defines the final rate of the charge consumption by the desired reaction. Hence, the overall photocatalytic activity is often limited by the degree of electronic communication between the semiconductor and the co-catalyst, and the accessibility of the catalytic active sites. In order to provide more control over the co-catalyst/semiconductor interface, co-catalyst species are often generated on the support surface via bottom-up methods such as photodeposition, chemical deposition and growth as well as a selective surface reaction. ${ }^{6-12}$ In many cases, the synthesis is accompanied by thermal treatments aiming to generate the desired co-catalyst species via oxidation or reduction. However, temperatures can facilitate otherwise kinetically 
hindered diffusion processes leading to possible growth of the co-catalyst species or their chemical interaction with the substrate. These processes can reduce the accessibility of the catalytic centers to the reactants and lead to doping which often creates charge recombination centers and introduces localized inter-bandgap states resulting in lower photocatalytic performance. ${ }^{13,14}$ It thus becomes important to control the location, chemical state and morphology of the co-catalyst species in the final photocatalytic system, for which more detailed investigations are often desired.

This work examines a series of Cu-based co-catalysts supported on anatase $\mathrm{TiO}_{2}$ as a model substrate and provides a comprehensive insight into the side effects of thermal pretreatments on their photocatalytic performance. The results reveal a surprising effect of the heat-treatment temperature on the hydrogen evolution reaction (HER) activity: the HER rates decrease at higher calcination temperatures, while the maximum activity is achieved for the non- and low-temperature treated samples, in contrast to other works. ${ }^{10,15,16}$ Aiming to unveil optimal synthetic parameters, we prepared a set of $\mathrm{Cu}$ / $\mathrm{TiO}_{2}$ composites via wet-chemical deposition of $\mathrm{Cu}$ species and characterized systematically their oxidation state, location and loading. To elucidate and understand the mechanism responsible for the photocatalytic performance, we correlated the rates of HER with the data obtained via photoelectron spectroscopy (XPS and UPS), infrared-, Raman- and diffuse reflectance spectroscopy (DRS), as well as microscopic techniques (TEM) and Xray diffraction (XRD), among others. Overall, our results reveal that higher calcination temperatures $\left(>200{ }^{\circ} \mathrm{C}\right)$ can trigger migration of the $\mathrm{Cu}$ species from the $\mathrm{TiO}_{2}$ surface to its subsurface and bulk. The disappearance of active sites as well as the introduction of defect sites can both be responsible for the observed HER decline. This work illustrates the importance of considering potential side effects of thermal treatments in the preparation and activation of non-noble-metal-containing cocatalysts and provides a quantitative measure for their impact on photocatalytic performance.

\section{Results and discussion}

We investigated the hydrogen evolution reaction (HER) for a series of nanoparticulate anatase $\mathrm{TiO}_{2}$ powders impregnated with $\sim 1$ at $\%$ of $\mathrm{Cu}$ as a function of thermal treatment. Two sample sets were prepared using different $\mathrm{Cu}$ precursors: copper acetate, $\mathrm{Cu}(\mathrm{ac})_{2}$, and copper nitrate, $\mathrm{Cu}\left(\mathrm{NO}_{3}\right)_{2}$. The asprepared $\mathrm{Cu}(\mathrm{ac})_{2} / \mathrm{TiO}_{2}$ and $\mathrm{Cu}\left(\mathrm{NO}_{3}\right)_{2} / \mathrm{TiO}_{2}$ powders were subjected to temperature-treatments ranging from room temperature (RT) - i.e. no thermal treatment - to $400{ }^{\circ} \mathrm{C}$ and evaluated with regard to their HER performance (Fig. 1a). The photocatalytic data revealed a clear trend for both sample sets: the activity first increased with calcination temperature to reach a maximum at $100{ }^{\circ} \mathrm{C} / 150{ }^{\circ} \mathrm{C}$, then by further increasing the temperature a gradual decrease of the HER takes place. The subsequent decrease at higher calcination temperatures, however, was surprising, considering that thermal treatments at those temperatures constitute a standard method required to either eliminate the anion residue, generate the corresponding oxides, or enhance the interaction between the substrate and co-catalyst. ${ }^{7,8,10-12,17,18}$ Yet, our data show that the calcination protocol of the $\mathrm{Cu} / \mathrm{TiO}_{2}$ composites has a detrimental effect on photocatalytic performance. In addition, a similar HER trend was observed for isothermal treatments performed at $250{ }^{\circ} \mathrm{C}$ for different periods of time (see Fig. S2 $\dagger$ ). Hence, not only does the temperature of the treatment play a role but also the time of calcination. For simplicity, as both parameters - temperature and time - led to similar behavior, in this work we focused on the effect of temperature, and thus we set a constant calcination time of $2 \mathrm{~h}$ for each thermally treated sample.

The observed HER decline in Fig. 1a can originate from several phenomena: (a) sintering of the $\mathrm{Cu}$ species on the $\mathrm{TiO}_{2}$ surface, (b) generation of less or non-active $\mathrm{Cu}$ species (change in the oxidation state/morphology) or (c) diffusion of $\mathrm{Cu}$ into the $\mathrm{TiO}_{2}$ lattice, which may lead to (d) reduced availability of the $\mathrm{Cu}$ sites at the solid-liquid interface, (e) formation of thermally induced defects that act as charge recombination centers (doping) or (f) changes of the band gap structure (electronic effect), among others. ${ }^{6,9-11,13,14,19-21}$ In order to elucidate the responsible factors for the observed HER trends, we thoroughly characterized and investigated both sample sets, $\mathrm{Cu}(\mathrm{ac})_{2} / \mathrm{TiO}_{2}$ and $\mathrm{Cu}\left(\mathrm{NO}_{3}\right)_{2} / \mathrm{TiO}_{2}$, with a plethora of methods.

\section{Thermal and morphological analysis}

The thermal gravimetric analysis (TGA) in Fig. 1b of the composites revealed that the decomposition of the anions takes place between $206{ }^{\circ} \mathrm{C}$ and $360{ }^{\circ} \mathrm{C}$ for $\mathrm{Cu}\left(\mathrm{NO}_{3}\right)_{2} / \mathrm{TiO}_{2}$ and $255{ }^{\circ} \mathrm{C}$ to $313{ }^{\circ} \mathrm{C}$ for $\mathrm{Cu}(\mathrm{ac})_{2} / \mathrm{TiO}_{2}$. The beginning of the anion decomposition coincides well with the start of the HER activity decline, which thus may be related to the precursor transformation. Yet, it is well known that the thermal treatment can also induce sintering of the $\mathrm{Cu}$ species that can lead to reduced activity. ${ }^{\mathbf{1 9}}$ High-resolution transmission electron microscopy (HRTEM) revealed that no Cu-based clusters or nanoparticles (NP) are present on the $\mathrm{TiO}_{2}$ surface, independent of the precursor type and the temperature of the thermal treatment (Fig. 1c-f). This suggests that $\mathrm{Cu}$ is homogeneously distributed on the $\mathrm{TiO}_{2}$ support at the nanoscale as atomic layers/species without forming TEM-visible clusters, even at high-temperature treatments. This eliminates sintering as a significant reason for the observed activity drop.

\section{Structural and compositional analysis}

The Raman spectrum in Fig. 2a shows only features that correspond to a pure anatase phase with the typical $\mathrm{E}_{\mathrm{g}}$ $\left(145.3 \mathrm{~cm}^{-1}\right), \mathrm{B}_{1 \mathrm{~g}}\left(397.5 \mathrm{~cm}^{-1}\right), \mathrm{A}_{1 \mathrm{~g}}+\mathrm{B}_{1 \mathrm{~g}}\left(517.5 \mathrm{~cm}^{-1}\right)$ and $\mathrm{E}_{\mathrm{g}}$ $\left(641.1 \mathrm{~cm}^{-1}\right)$ bands, which belong to the O-Ti-O symmetric stretching, symmetric bending and antisymmetric bending vibrations, respectively. ${ }^{22,23}$ This indicates that neither the transition to rutile nor the formation of a separate $\mathrm{Cu}$ phase took place in any of the samples (further confirmed by XRD, see Fig. S7†). Furthermore, a gradual decrease of the $\mathrm{TiO}_{2}$ band intensities with increasing calcination temperatures occurred for both samples, accompanied by a broadening of their FWHM, yet with some fluctuations (Fig. 2b and c). The loss of 
a)

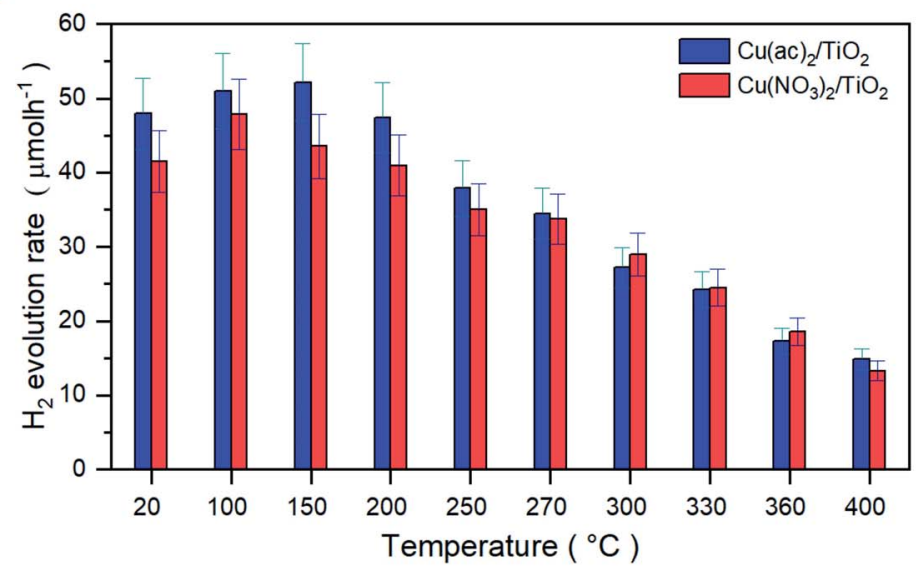

b)

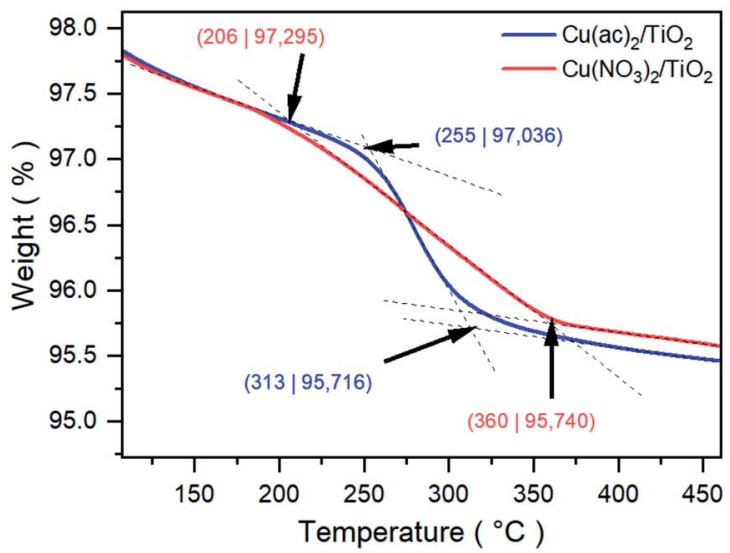

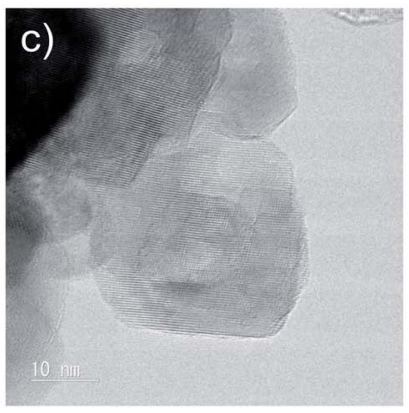
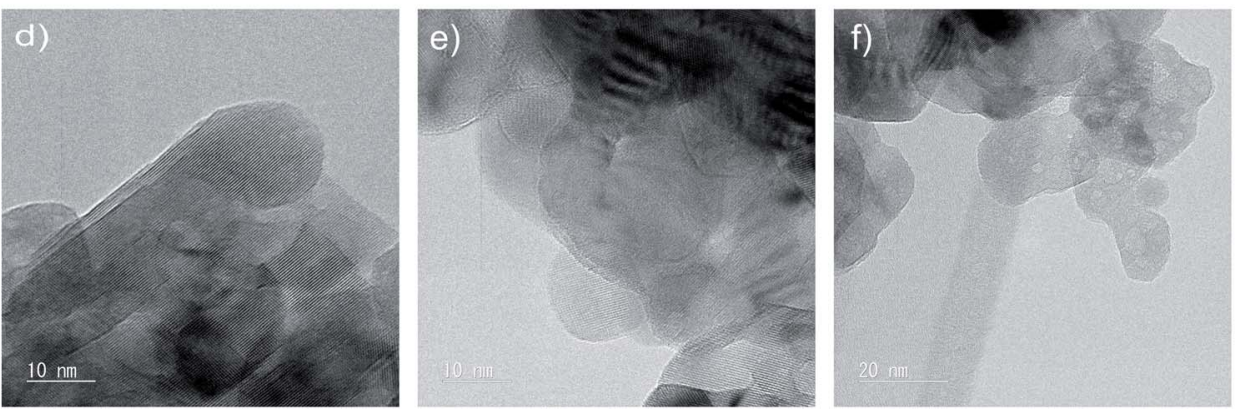

Fig. 1 (a) Values of the HER rates achieved after 20 minutes of illumination of $\mathrm{Cu}(\mathrm{ac})_{2} / \mathrm{TiO}_{2}$ and $\mathrm{Cu}\left(\mathrm{NO}_{3}\right)_{2} / \mathrm{TiO}_{2}$ composite series prepared at different temperatures. Full HER evolution profiles over time and illumination are shown in Fig. S1 and Table S1, $\uparrow$ HER stability (long-term HER performance) discussion can be found in Fig. $\mathrm{S} 3, \uparrow$ (b) TGA profiles of the $\mathrm{Cu}(\mathrm{ac})_{2} / \mathrm{TiO}_{2}$ and $\mathrm{Cu}\left(\mathrm{NO}_{3}\right)_{2} / \mathrm{TiO}_{2}$ composites showing the decomposition ranges from 206 to $360{ }^{\circ} \mathrm{C}$ and 255 to $313{ }^{\circ} \mathrm{C}$, respectively. Full profiles from room temperature to $800^{\circ} \mathrm{C}$ are shown in Fig. S4. $\dagger$ (c) HRTEM images of anatase- $\mathrm{TiO}_{2}$, (d) the non-calcined, (e) $400{ }^{\circ} \mathrm{C}(10 \mathrm{~nm})$ and (f) $400{ }^{\circ} \mathrm{C}$ calcined (20 nm) Cu/TiO 2 composites. Further TEM and complementary SEM micrographs are shown in Fig. S5 and S6.†

Raman band intensity can be related to a decrease in polarizability and symmetry of the vibrational modes and suggests a crystal lattice distortion of $\mathrm{TiO}_{2}$, which is more pronounced at higher temperatures. ${ }^{22,24-30}$ The slight FWHM broadening of the $\mathrm{Cu} / \mathrm{TiO}_{2}$ samples - in contrast to bare $\mathrm{TiO}_{2}$ - further confirms this assumption (Fig. 2d). ${ }^{22,25,26}$ Furthermore, recent DFT studies revealed that $\mathrm{Cu}$ incorporation (via interstitial or substitutional $\mathrm{Cu}: \mathrm{TiO}_{2}$ doping) does not result in a strong $\mathrm{TiO}_{2}$ lattice distortion. ${ }^{31}$ Hence, these observations point to the possible formation of thermally induced $\mathrm{Cu}-\mathrm{TiO}_{2}$ lattice defects, via $\mathrm{Cu}$ surface-to-bulk diffusion, which - being a kinetically hindered process - can be activated at higher temperatures. ${ }^{27-29}$

Attenuated total reflection infrared (ATR-IR) spectroscopy of the composites, Fig. 3, indicates chemisorption of the $\mathrm{Cu}$ precursor species on the $\mathrm{TiO}_{2}$ surface already after impregnation (RT samples). This is evident from the red-shifted COO modes of the acetate ligand (around 1490 and $1600 \mathrm{~cm}^{-1}$ ), the appearance $\left(1558 \mathrm{~cm}^{-1}\right)$ and decrease $\left(1419 \mathrm{~cm}^{-1}\right)$ of a new acetate binding mode, and the pronounced rise of the intensity of the bidentate bridging nitrate coordination at $1620 \mathrm{~cm}^{-1}$, typical artifacts of surface-binding. ${ }^{32}$ Furthermore, at $400{ }^{\circ} \mathrm{C}$ we see a complete decomposition of the nitrate and acetate ligands, in line with TGA.
Fig. 1a shows that the highest photocatalytic activity was obtained at $150{ }^{\circ} \mathrm{C}$ for $\mathrm{Cu}(\mathrm{ac})_{2} / \mathrm{TiO}_{2}$ and $100{ }^{\circ} \mathrm{C}$ for $\mathrm{Cu}\left(\mathrm{NO}_{3}\right)_{2} /$ $\mathrm{TiO}_{2}$. Based on the discussion above, Raman signal changes are already visible at these temperatures and ATR-IR indicates strong binding of the precursor species, yet no $\mathrm{Cu}$ diffusion is expected at those temperatures. Hence, we suggest that such mild thermal treatments enact densification of the adsorbed precursor layer, resulting in $\mathrm{Cu}$ species that are bound more strongly to the $\mathrm{TiO}_{2}$ surface. This in turn induces a slight crystal distortion at the $\mathrm{Cu} / \mathrm{TiO}_{2}$ interface (inducing the Raman signal changes) but concomitantly enhances the electronic communication between the support and the co-catalyst, leading to a better overall HER performance.

\section{Surface-to-bulk diffusion}

In order to further investigate a possible formation of $\mathrm{Cu}-\mathrm{TiO}_{2}$ lattice defects upon calcination (indicated by Raman spectroscopy), we analyzed the samples with X-ray photoelectron spectroscopy (XPS). The idea is that diffusion of $\mathrm{Cu}$ from the surface into the bulk would lead to a decreased $\mathrm{Cu}$ concentration on the substrate surface and hence to a weaker $\mathrm{Cu}$ signal in the surface-sensitive XPS. Moreover, XPS also allows for identifying changes in the oxidation state of $\mathrm{Cu}$ and $\mathrm{Ti}$. 
a)

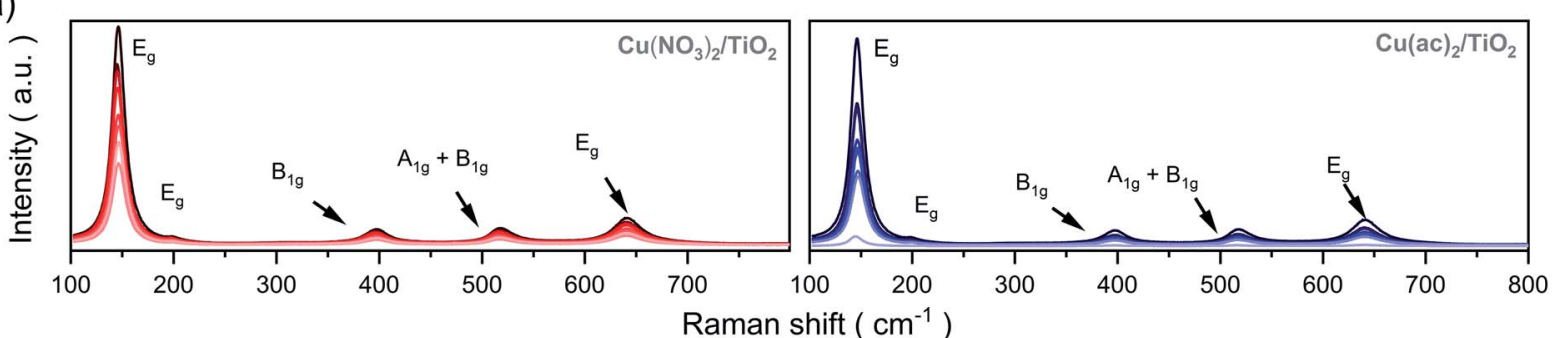

b)

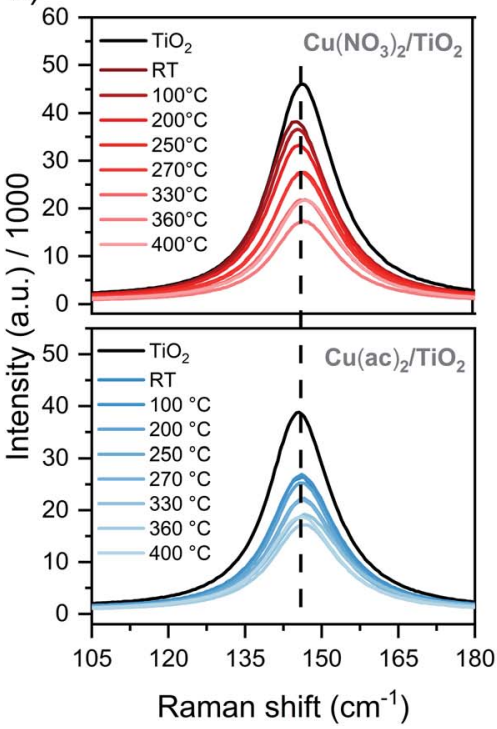

C)

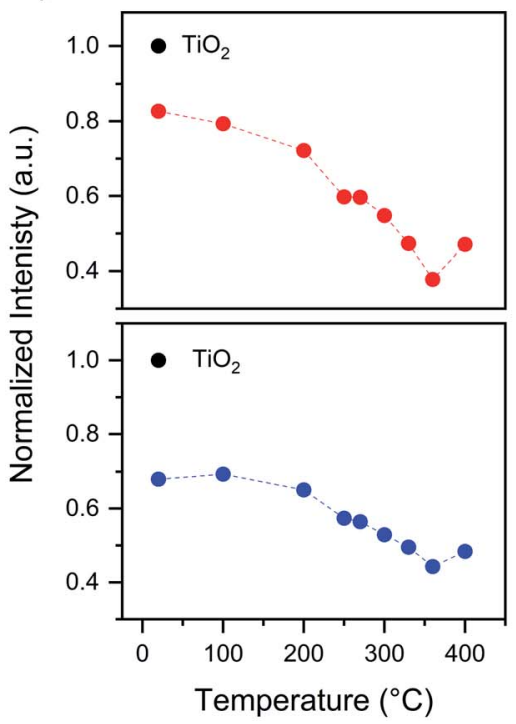

d)

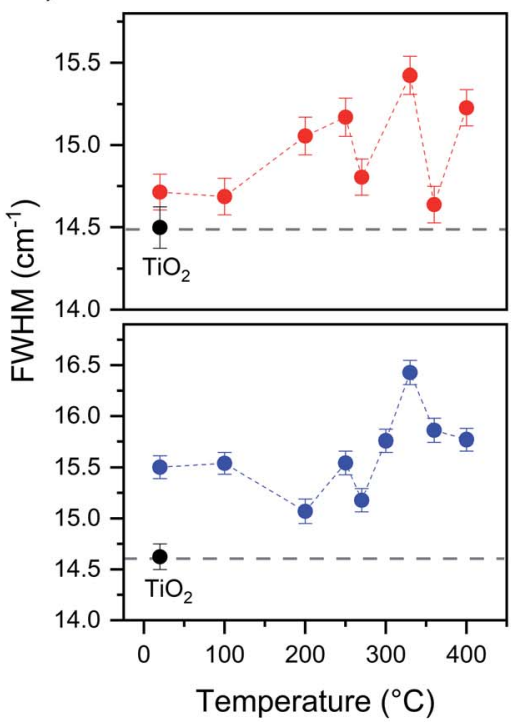

Fig. 2 Raman data of the $\mathrm{Cu}\left(\mathrm{NO}_{3}\right)_{2} / \mathrm{TiO}_{2}$ (red) and $\mathrm{Cu}(\mathrm{ac})_{2} / \mathrm{TiO}_{2}$ (blue) composites as a function of post-thermal treatment temperature: (a) full range of the $\mathrm{Cu}\left(\mathrm{NO}_{3}\right)_{2} / \mathrm{TiO}_{2}$ and $\mathrm{Cu}(\mathrm{ac})_{2} / \mathrm{TiO}_{2}$ composites, (b) $\mathrm{E}_{\mathrm{g}}$ band profiles, (c) normalized $\mathrm{E}_{\mathrm{g}}$ band intensity - to bare TiO $\mathrm{T}_{2}$ to exclude instrumental artifacts - and (d) $\mathrm{E}_{\mathrm{g}}$ band FWHM changes. Details in Table S2. $\dagger$

a)

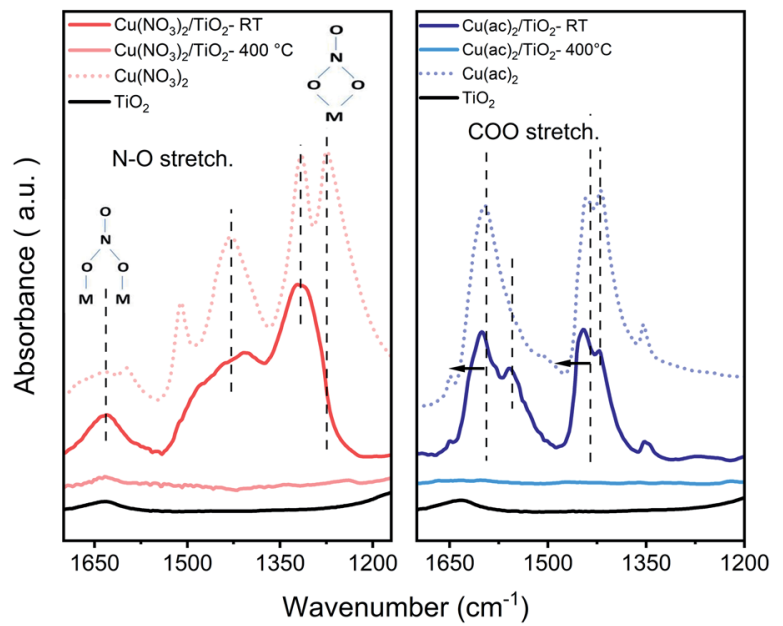

Fig. 3 FTIR-ATR of (a) $\mathrm{Cu}\left(\mathrm{NO}_{3}\right)_{2} / \mathrm{TiO}_{2}$ and (b) $\mathrm{Cu}(\mathrm{ac})_{2} / \mathrm{TiO}_{2}$ samples. Main nitrate and acetate peaks, showing the new binding modes and band shift for the non-calcined (RT) and calcined at $400{ }^{\circ} \mathrm{C}$ composites vs. the pure precursors and $\mathrm{TiO}_{2}$. Samples contained 5 at\% of $\mathrm{Cu}$, to obtain a better visualization. The full range of the pure precursor, 5 at\% Cu and 1 at\% Cu samples are shown in Fig. S8 and S9. $\dagger$
The survey spectra acquired show the expected $\mathrm{Cu} 2 \mathrm{p}, \mathrm{Cu}$ Auger, Ti 2p, C 1s and O 1s signals for all measured samples. The detail spectra of $\mathrm{C} 1 \mathrm{~s}$ and $\mathrm{O} 1 \mathrm{~s}$ show the typical carbon species as well as the oxygen from $\mathrm{TiO}_{2}$ (Fig. S10-S13 $\dagger$ ). The Ti $2 \mathrm{p}_{3 / 2}$ signal $(458.8 \mathrm{eV})$ corresponds to $\mathrm{Ti}^{4+}$ in all samples, with no detectable contribution of $\mathrm{Ti}^{3+}$ (Fig. 4e). The $\mathrm{Cu} 2 \mathrm{p}$ signals, however, are more complex and surprising, as no characteristic $\mathrm{Cu}^{2+}$ satellite features (generally around $942 \mathrm{eV}$ ) were detectable, despite $\mathrm{Cu}^{2+}$ precursors being used in the synthesis (Fig. 4a and b).$^{33-35}$ Thus, the $\mathrm{Cu} 2 \mathrm{p}_{3 / 2}$ peaks, seen in all samples $\left(932.5 \mathrm{eV}\right.$ for $\mathrm{Cu}\left(\mathrm{NO}_{3}\right)_{2} /$ $\mathrm{TiO}_{2}$ and $932.3 \mathrm{eV}$ for $\left.\mathrm{Cu}(\mathrm{ac})_{2} / \mathrm{TiO}_{2}\right)$, indicate the presence of $\mathrm{Cu}^{+}$, $\mathrm{Cu}^{0}$ or more likely a combination of both. However, considering the low signal intensity - due to the low ( $\sim 1$ at $\%)$ Cu content and the slight asymmetric broadening of the signal, the presence of small amounts of $\mathrm{Cu}^{2+}$ cannot be fully excluded. In fact, DRS discussed later in the manuscript - confirms the presence of $\mathrm{Cu}^{2+}$. To further clarify the $\mathrm{Cu}$ oxidation states in the composites, we also analyzed the Cu LMM Auger signals shown in Fig. 4c. However, it was only possible to obtain a reliable signal for the non-calcined and $250{ }^{\circ} \mathrm{C}$ treated samples. Furthermore, as the binding energy and Auger parameters are sensitive to the ligand nature and small particle size, only qualitative analysis was performed to confirm the $\mathrm{Cu} 2 \mathrm{p}_{3 / 2}$ signal analysis. ${ }^{34,35}$ The data reveal a sharp and intense peak at $915.1 \mathrm{eV}$ kinetic energy (K.E.), 
a)

d)

b)

Binding energy ( $\mathrm{eV}$ )
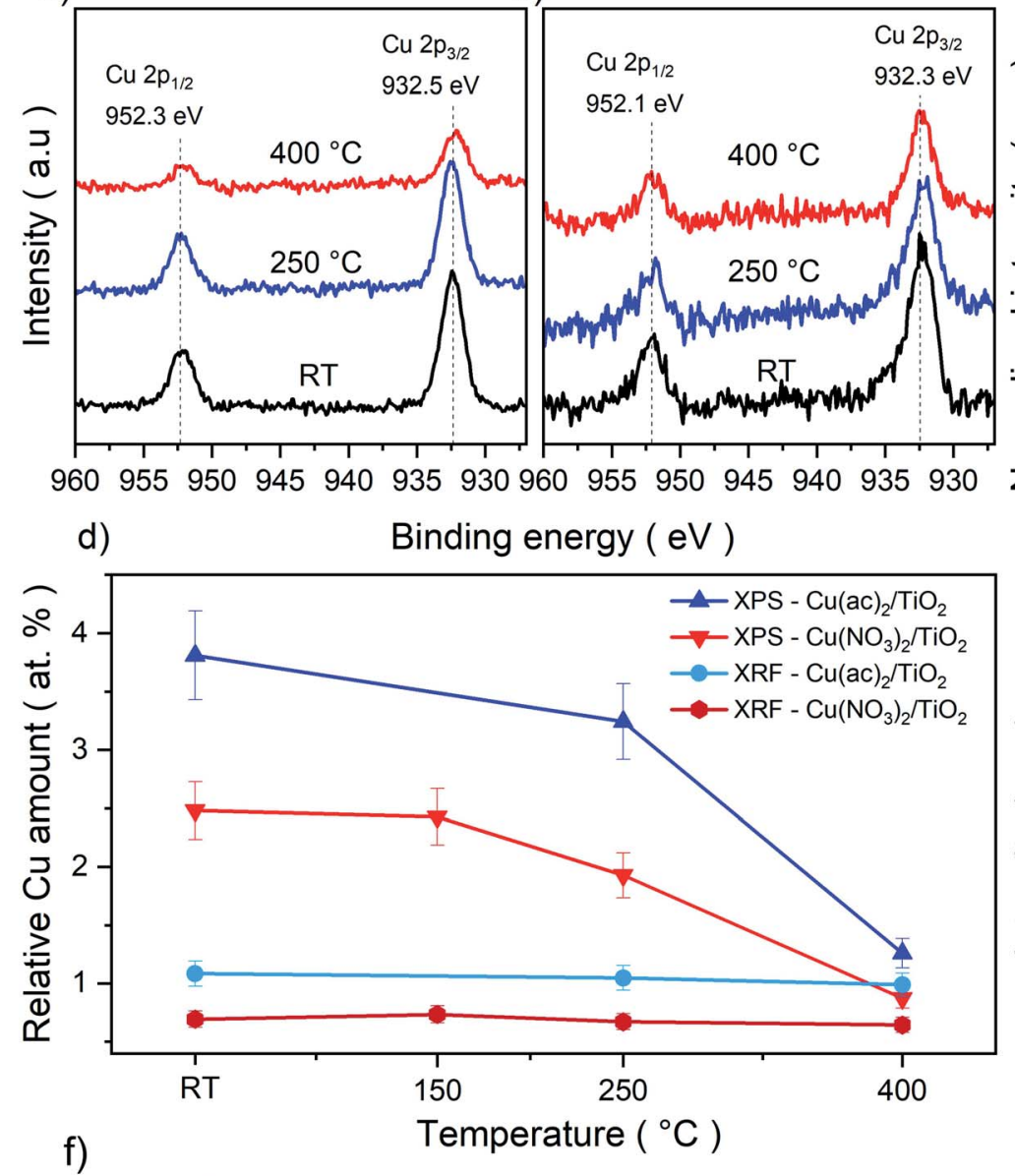

f) c)

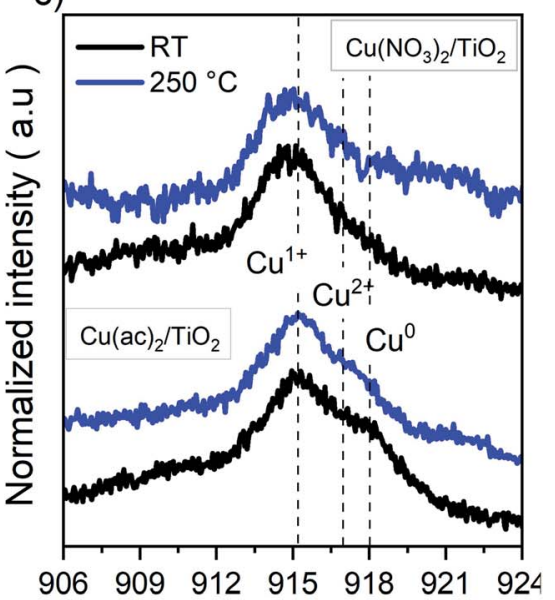

e) Kinetik energy ( $\mathrm{eV}$ )

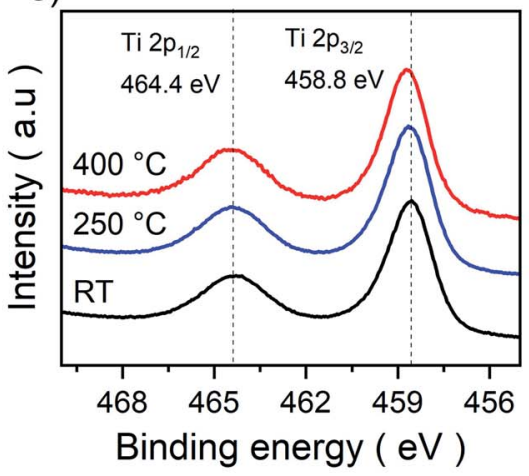

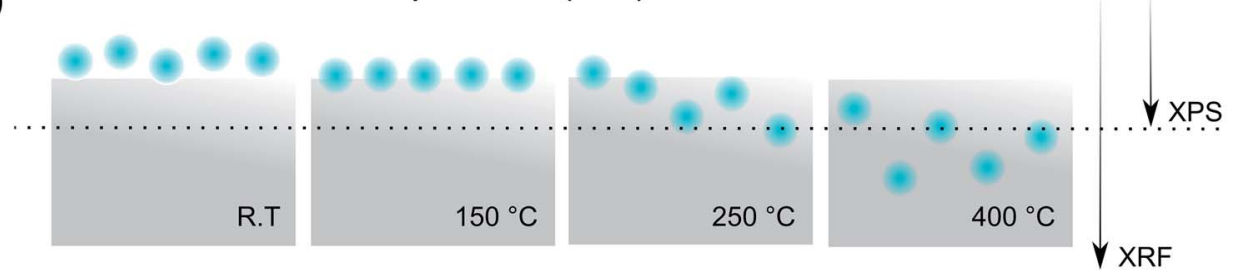

$\mathrm{Cu}$

$\mathrm{TiO}_{2}$

Fig. 4 XPS Cu 2p detail spectra of the (a) $\mathrm{Cu}\left(\mathrm{NO}_{3}\right)_{2} / \mathrm{TiO}_{2}$ and (b) $\mathrm{Cu}(\mathrm{ac})_{2} / \mathrm{TiO}_{2}$ composites subjected to various temperature treatments. (c) $\mathrm{Cu}$ LMM Auger spectra for both composites non-calcined (RT) and at $250{ }^{\circ} \mathrm{C}$. The $\mathrm{Cu}^{2+}, \mathrm{Cu}^{+}$and $\mathrm{Cu}^{0}$ reference values were taken from literature reports. ${ }^{33-35}$ (d) Elemental Cu contents (Cu-to-Ti ratio in at\%) derived from bulk sensitive XRF and surface-sensitive XPS survey data. Absolute values are shown in Table S5. $\dagger$ (e) Ti $2 p$ spectra of the composites and (f) graphical representation of the proposed thermally induced diffusion mechanism and depth penetration of XPS and XRF.

which corresponds to $\mathrm{Cu}^{+} .^{33,36}$ At $918 \mathrm{eV}$ K.E. a clear shoulder, typical of $\mathrm{Cu}^{0}$, is visible for the non-calcined $\mathrm{Cu}(\mathrm{ac})_{2} / \mathrm{TiO}_{2}$; the shoulder, however, almost disappears after the $250{ }^{\circ} \mathrm{C}$ treatment. Besides, as $\mathrm{Cu}^{2+}$ generally appears around $\sim 917 \mathrm{eV}$, the broadening in that region of the spectrum further indicates the presence of $\mathrm{Cu}^{0}$ and $\mathrm{Cu}^{2+}$. Overall, we conclude, that a mixture of $\mathrm{Cu}^{2+}, \mathrm{Cu}^{+}$and $\mathrm{Cu}^{0}$ is present in all the $\mathrm{Cu} / \mathrm{TiO}_{2}$ samples with $\mathrm{Cu}^{+}$ being the most abundant. The presence of a mixed oxidation state implies that a reduction of the original $\mathrm{Cu}^{2+}$ precursor takes place already during impregnation most probably induced by the photoelectrons of $\mathrm{TiO}_{2}$ generated under ambient light (further discussion in the optoelectronic analysis and DFT sections) and by the set of our synthetic conditions (i.e. use of vacuum and ethanol).
To further elaborate on the hypothesis of possible $\mathrm{Cu}$ diffusion into the substrate lattice, we compared the $\mathrm{Cu}$ amounts quantified from XPS (a surface-sensitive method) against the elemental quantification obtained using X-ray fluorescence (XRF) spectroscopy (a bulk-sensitive method, considering the nanometer-sized composites), shown in Fig. $4 \mathrm{~d}$ and $\mathrm{f}$. The XRF $\mathrm{Cu}$ signal of $\sim 1$ at $\%$ is consistent for all composites (noncalcined and calcined at 150, 250 and $400{ }^{\circ} \mathrm{C}$ ), while the $\mathrm{Cu}$ content in XPS decreased strongly from 2.5 to $0.9 \mathrm{Cu}$ at $\%$ ( $\mathrm{Ti}$ is set to $100 \%$ and $\mathrm{Cu}$ content is provided in relation to it). Overall, while XRF confirms that no $\mathrm{Cu}$ loss from the sample takes place upon calcination, these complementary sets of data suggest that $\mathrm{Cu}$ undergoes diffusion into the $\mathrm{TiO}_{2}$ lattice at higher calcination temperatures. 


\section{Analysis of the optoelectronic properties}

The DRS data in Fig. 5a and b reveal a strong absorption band below $400 \mathrm{~nm}$, which corresponds to the ligand-to-metal charge transfer (LMCT) of oxygen $\left(\mathrm{O}^{2-}\right)$ to $\mathrm{Ti}^{4+}$ and $\mathrm{Cu}^{n+}(n=0,1$ or 2). ${ }^{37,38}$ Next, all samples show a shoulder in the range of 400 to $500 \mathrm{~nm}$, absent in pure $\mathrm{TiO}_{2}$. The nature of this band is strongly debated in literature and has been attributed to localized surface plasmon resonance (LSPR) effects of $\mathrm{Cu}^{0}$ nanoparticles (NP), d-s transition of $\mathrm{Cu}^{0}\left(\mathrm{~d}^{10} \mathrm{~s}^{1}\right)$, interfacial charge transfer (IFCT) from the $\mathrm{TiO}_{2}$ valence band (VB) to the $\mathrm{Cu}^{2+}$ ions or $\mathrm{Cu}_{x} \mathrm{O}$-clusters as well as to $\mathrm{Cu}^{+}$metal-to-ligand charge transfer (MLCT) absorption. ${ }^{38-43}$ In our case, TEM micrographs show no visible $\mathrm{Cu}$ nanoparticles. Thus, NP LSPR effects can be excluded. DFT calculations revealed that this shoulder a)

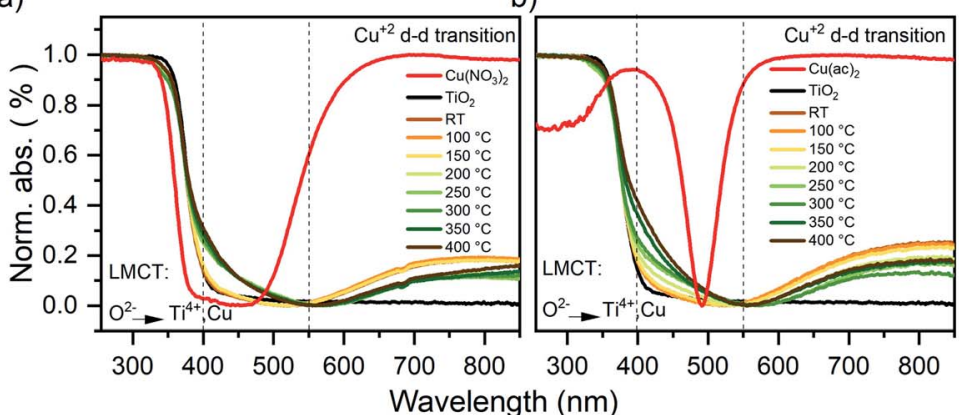

c)

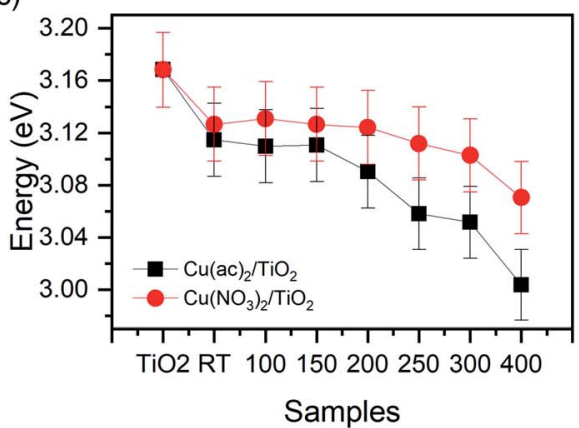

d)

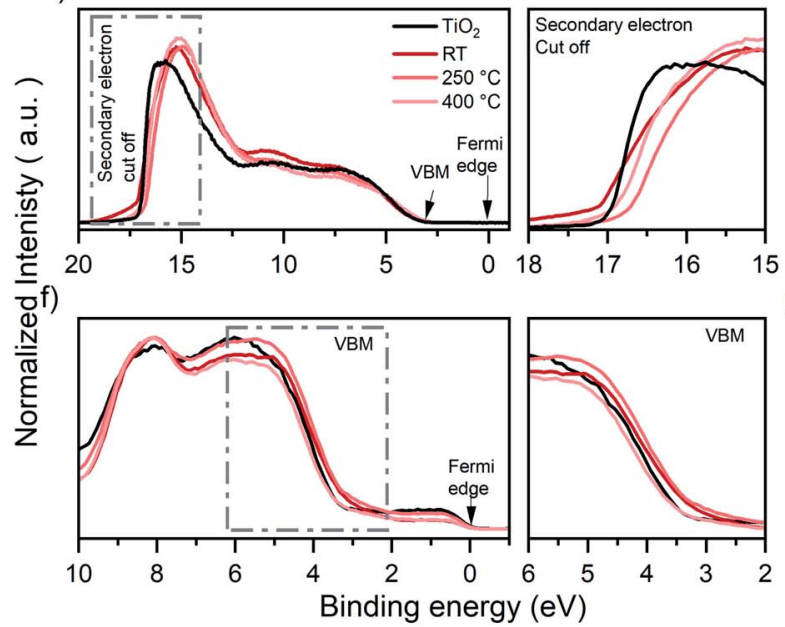

e)

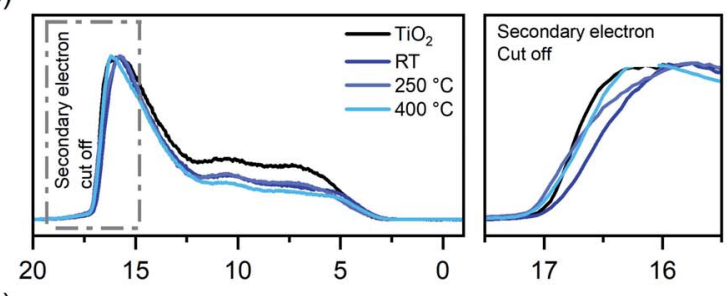

g)

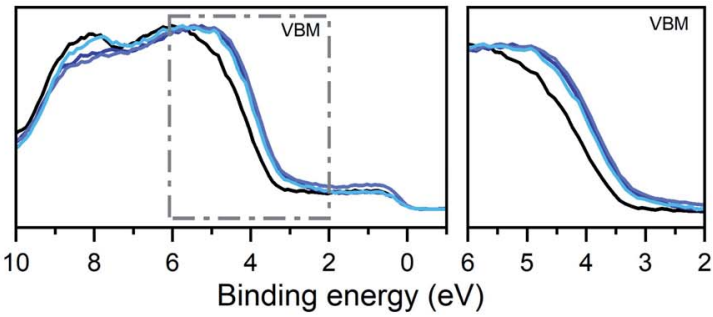

h)

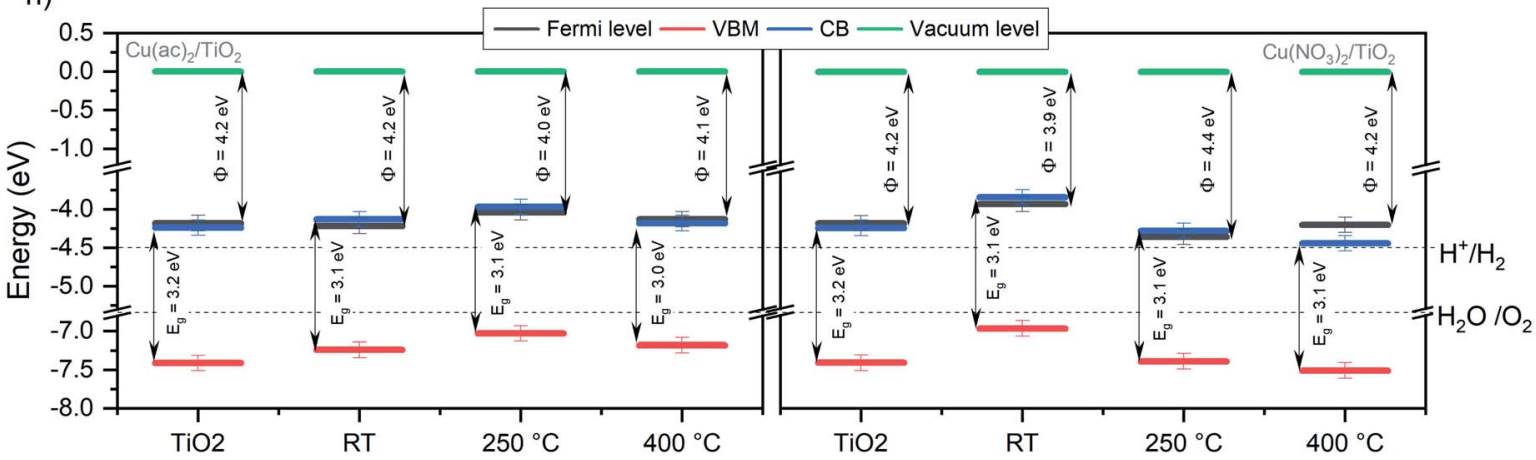

Fig. 5 Normalized DRS data for the (a) $\mathrm{Cu}\left(\mathrm{NO}_{3}\right)_{2} / \mathrm{TiO}_{2}$ and (b) $\mathrm{Cu}(\mathrm{ac})_{2} / \mathrm{TiO}_{2}$ composites subjected to various thermal treatments along with the pure anatase $\mathrm{TiO}_{2}$ and the original $\mathrm{Cu}$ precursors. (c) Band gap $\left(E_{\mathrm{g}}\right)$ values of the $\mathrm{Cu}\left(\mathrm{NO}_{3}\right)_{2} / \mathrm{TiO}_{2}$ and $\mathrm{Cu}(\mathrm{ac})_{2} / \mathrm{TiO} \mathrm{O}_{2} \mathrm{Composites}$ as a function of post-treatment temperature. The data is extracted via Tauc plot analysis of the DRS spectra. RT = non-calcined sample, LMCT = ligand to metal charge transfer. Further details, absolute values of the composites and thermal evolution of the pure precursors are shown in Fig. S15, S16 and Table S6. $\dagger$ (d) UPS signals of $\mathrm{Cu}\left(\mathrm{NO}_{3}\right)_{2} / \mathrm{TiO}_{2}$ and (e) $\mathrm{Cu}(\mathrm{ac})_{2} / \mathrm{TiO}_{2}$ composites prepared at different temperatures. (f) $\mathrm{VB}-\mathrm{XPS}$ of $\mathrm{Cu}\left(\mathrm{NO} \mathrm{O}_{3} / \mathrm{TiO}_{2}\right.$ and (g) $\mathrm{Cu}(\mathrm{ac})_{2} / \mathrm{TiO}_{2}$ composites. (h) Energy diagram (energy (eV) vs. vacuum level) of $\mathrm{Cu}(\mathrm{ac})_{2} / \mathrm{TiO}_{2}$ and $\mathrm{Cu}\left(\mathrm{NO}_{3}\right)_{2} / \mathrm{TiO} \mathrm{O}_{2} \mathrm{constructed}$ from the corresponding UPS, XPS and DRS data (further detail in Fig. S17 and Table S7 $\dagger$ ) of the bare $\mathrm{TiO}_{2}$-anatase, the non-calcined sample and the composites obtained via calcination at different temperature. $\mathrm{H}^{+} / \mathrm{H}_{2}$ and $\mathrm{H}_{2} \mathrm{O} / \mathrm{O}_{2}$ potential values taken at standard conditions. ${ }^{52,53} \mathrm{Note}$ that the values are referenced to the vacuum level $\left(E_{\mathrm{vac}}=0 \mathrm{eV}\right)$. 
originates from inter-band gap states of $\mathrm{Cu}-\mathrm{d}$ orbitals caused by $\mathrm{Cu}^{0}, \mathrm{Cu}^{+}$and $\mathrm{Cu}^{2+}$ (see the corresponding section for further discussion). The strong absorption between 550 and $900 \mathrm{~nm}$ is characteristic of $\mathrm{Cu}^{2+} \mathrm{d}-\mathrm{d}$ transitions $\left(\mathrm{d}^{9} \mathrm{~s}^{0}\right.$ ) (see pure $\mathrm{Cu}^{2+}$ precursors reference in Fig. $5 \mathrm{a}$ and b)..$^{37,39,44}$ This further corroborates the presence of $\mathrm{Cu}^{2+}$ in the composites. Furthermore, the $\mathrm{d}-\mathrm{d} \mathrm{Cu}^{2+}$ band intensity decreases by increasing temperature. This reveals that $\mathrm{Cu}^{2+}$ vanishes from the composites at higher calcination temperatures, in line with the heat-induced diffusion of $\mathrm{Cu}$ into $\mathrm{TiO}_{2}$, indicated by XPS and XRF as well as DFT models discussed later.

The optical band gaps constructed from the corresponding DRS data, determined by using Tauc plots (Fig. 5c), revealed a clear band gap decrease with increasing temperature. ${ }^{45}$ Yet, already a decrease for the non-calcined samples takes place from $3.17 \mathrm{eV}$, for bare $\mathrm{TiO}_{2}$, to $3.12 \mathrm{eV}$ and $3.13 \mathrm{eV}$ for $\mathrm{Cu}(\mathrm{ac})_{2} /$ $\mathrm{TiO}_{2}$ and $\mathrm{Cu}\left(\mathrm{NO}_{3}\right)_{2} / \mathrm{TiO}_{2}$, respectively. This also confirms the presence of $\mathrm{Cu}$ inter-band gap states and suggests that electronic communication between $\mathrm{TiO}_{2}$ and $\mathrm{Cu}$ was established immediately after impregnation - in line with Raman spectroscopy - and gets more pronounced with increasing temperature. These findings align well with the hypothesis of thermally induced diffusion of the $\mathrm{Cu}$ species into the $\mathrm{TiO}_{2}$ lattice and previously reported studies on $\mathrm{Cu}$ doped $\mathrm{TiO}_{2} \cdot{ }^{46,47}$

The work function and valence band maximum (VBM) of the samples were determined using UPS and XPS (see Fig. $5 \mathrm{~d}-\mathrm{h}$ and for further detail about the method Fig. S17†). ${ }^{48}$ The data show strong fluctuations in the work function values, without following a clear trend, while the VBM shows a decrease for all samples except $\mathrm{Cu}\left(\mathrm{NO}_{3}\right)_{2} / \mathrm{TiO}_{2}$ at $400{ }^{\circ} \mathrm{C}$, which increases (see Table 1). Furthermore, the energy diagrams, constructed based on XPS, UPS and DRS, show that the Fermi level of all samples, except $\mathrm{Cu}\left(\mathrm{NO}_{3}\right)_{2} / \mathrm{TiO}_{2}$ calcined at $400{ }^{\circ} \mathrm{C}$, is in the same range as the conduction band minimum (CB) (see Fig. 5h), indicating an n-type conductivity of all samples. This can be related to an electron accumulation on the surface, which induces a downward band bending, attributed to defects (oxygen vacancies, titanium interstitials, etc.), adsorbed species (type and density of those species), UHV conditions or doping. ${ }^{4-52}$ This electron accumulation on the $\mathrm{TiO}_{2}$ surface would explain the reduction of $\mathrm{Cu}^{2+}$ to $\mathrm{Cu}^{+}$and $\mathrm{Cu}^{0}$ seen in XPS even for the non-thermally treated $\mathrm{Cu} / \mathrm{TiO}_{2}$ composites. Furthermore, to fully understand the work function differences between the composites prepared using different $\mathrm{Cu}$ precursors is beyond the scope of this study, yet it is well known that the work function depends on the

Table 1 Cut off, work function and valence band maximum (VBM) values obtained from the corresponding UPS and VB-XPS data shown in Fig. 5. All values are in eV. Details of the data evaluation method are shown in Fig. S17. RT = non-calcined sample

\begin{tabular}{|c|c|c|c|c|c|c|}
\hline & \multicolumn{3}{|c|}{$\mathrm{Cu}\left(\mathrm{NO}_{3}\right)_{2} / \mathrm{TiO}_{2}$} & \multicolumn{3}{|c|}{$\mathrm{Cu}(\mathrm{ac})_{2} / \mathrm{TiO}_{2}$} \\
\hline & Cut off & Work function & VBM & Cut off & Work function & VBM \\
\hline $\mathrm{TiO}_{2}$ & 17.0 & 4.2 & 3.2 & - & - & - \\
\hline RT & 17.3 & 3.9 & 3.0 & 17.0 & 4.2 & 3.0 \\
\hline $250^{\circ} \mathrm{C}$ & 16.8 & 4.4 & 3.0 & 17.2 & 4.0 & 3.0 \\
\hline $400{ }^{\circ} \mathrm{C}$ & 17.0 & 4.2 & 3.3 & 17.1 & 4.1 & 3.1 \\
\hline
\end{tabular}

surface structure and nature of the adsorbates. ${ }^{48,49}$ Hence, the presence of the different physisorbed anions (nitrate and acetate, that have different charge density and dipole moments), the products of the anion thermal decomposition and the different state and location of $\mathrm{Cu}$ is likely to affect the work function differently giving rise to these fluctuations. ${ }^{48}$ By correlating these data with the photocatalytic performance, we conclude that the position of the CB levels thermodynamically required to drive proton reduction remains suitable for all composites and does not seem to correlate with the observed HER trend. Yet, doping is known to induce defects that act as charge recombination centers; thus, the observed HER activity decrease can be governed by the $\mathrm{Cu}$-induced defects which increase by increasing temperature, rather than the change in the optoelectronic properties. ${ }^{13,51,53}$

\section{Analysis of the $\mathrm{Cu}-\mathrm{TiO}_{2}$ linkage strength}

Diffusion of $\mathrm{Cu}$ into the interior of the $\mathrm{TiO}_{2}$ particles will reduce their accessibility and improve their stability towards leaching into solution. Therefore, we performed washing experiments and analyzed the samples with DRS and XRF. DRS in Fig. 6a shows that the absorption band characteristic of $\mathrm{Cu}^{2+}$ (550 to $900 \mathrm{~nm}$ ) decreased significantly after washing with water for the non-treated sample and those heated at low temperature, suggesting a significant portion of weakly bound $\mathrm{Cu}^{2+}$ species. In contrast, a far smaller amount of $\mathrm{Cu}$-species detached in the samples treated at temperatures above $250{ }^{\circ} \mathrm{C}$. XRF (Fig. 6b) confirmed that $62.5 \%$ and $86.3 \%$ of $\mathrm{Cu}$ was removed from the non-calcined samples for $\mathrm{Cu}(\mathrm{ac})_{2} / \mathrm{TiO}_{2}$ and $\mathrm{Cu}\left(\mathrm{NO}_{3}\right)_{2} / \mathrm{TiO}_{2}$, a)

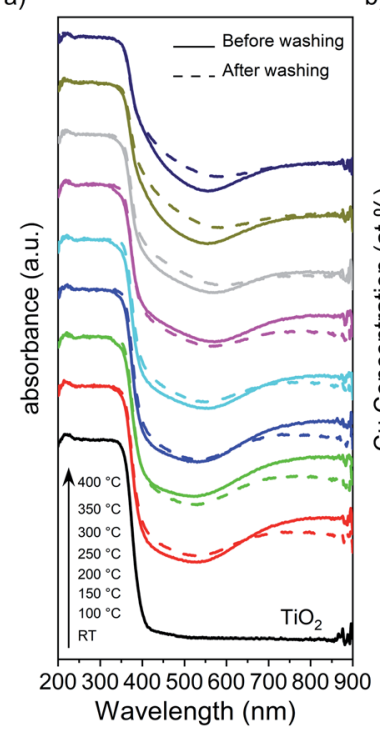

b)

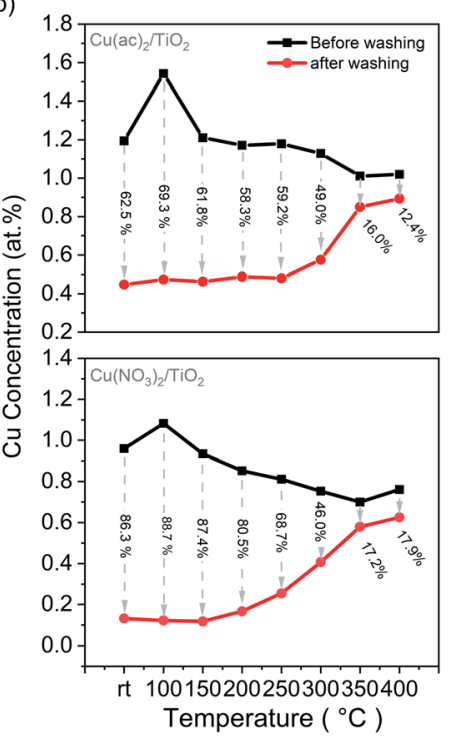

Fig. 6 Washing experiments of the $\mathrm{Cu} / \mathrm{TiO}_{2}$ composites: (a) DRS of the $\mathrm{Cu}(\mathrm{ac})_{2} / \mathrm{TiO}_{2}$ sample before and after washing. The corresponding DRS data of the $\mathrm{Cu}\left(\mathrm{NO}_{3}\right)_{2} / \mathrm{TiO}_{2}$ sample, showing the same behaviour, is shown in Fig. S18.† (b) XRF analysis of the Cu content before and after washing with the amount of $\mathrm{Cu}$ washed out (in \% regarding the original content). Further details are shown in Table S8. $\dagger$ 
respectively, while the corresponding amounts for the samples treated at $350{ }^{\circ} \mathrm{C}$ were only $16.0 \%$ and $17.2 \%$, respectively.

These results indicate that most of the $\mathrm{Cu}$ species are weakly bound on the surface and that the lower extent of leaching at high temperatures is a result of $\mathrm{Cu}$ surface-to-bulk diffusion. However, the observed band gap narrowing, VBM position shifts, as well as FTIR and Raman band changes indicate that $\mathrm{Cu}$-to-support interactions exist to some extent already for the non-calcined sample. Hence, despite $\mathrm{Cu}$ being weakly chemisorbed after impregnation, this interaction appears to be strong enough to establish efficient electronic communication with the supporting $\mathrm{TiO}_{2}$. Accordingly, the HER maximum for the catalysts calcined at mild temperatures can be associated with densification of the adsorbed species on the surface, which leads to a stronger binding that facilitates charge transfer from $\mathrm{TiO}_{2}$ to the catalytic center, Cu. The increase of calcination temperature above $200{ }^{\circ} \mathrm{C}$, however, triggers $\mathrm{Cu}$ diffusion into the $\mathrm{TiO}_{2}$ lattice, which consequently increases the number of charge recombination centers within $\mathrm{TiO}_{2}$ and reduces the number of $\mathrm{Cu}$ centers available on the surface. ${ }^{\mathbf{1 3 , 1 4}}$ Previous reports have shown that $\mathrm{Cu}$ undergoes redox shuttling between the reactant and the $\mathrm{TiO}_{2}$ surface by going into solution and redepositing by electron transfer from the $\mathrm{TiO}_{2} \mathrm{CB}$ to $\mathrm{Cu}^{9,54}$ Additional photodeposition experiments indicate that this mechanism is relevant to our system (further discussion in ESI and Fig. S19†). Therefore, we can conclude that both, the reduced availability of $\mathrm{Cu}$ sites on the surface as well as the introduction of new trap and recombination states in $\mathrm{TiO}_{2}$ lattice, contribute to the HER performance decline.

\section{DFT calculations}

Cu oxidation state and diffusion mechanism. To better understand the surface and sub-surface $\mathrm{Cu}$ incorporation, we performed DFT calculations (see details in Methods). We examined the formation stability and analyzed the oxidation states of the corresponding $\mathrm{Cu}$ atoms by following the changes in the magnetic moments and Bader charges. We considered various $\mathrm{Cu}$ models anchored to the most abundant and stable (101) anatase $\mathrm{TiO}_{2}$ surface: a single $\mathrm{Cu}$ atom, a cluster of $\mathrm{Cu}$ atoms and $\mathrm{Cu}$ clusters with different numbers of oxygen atoms coordinated to $\mathrm{Cu}$, labeled $\mathrm{Cu}_{y} \mathrm{O}_{x}$ (simulating partially oxidized clusters).

For a single $\mathrm{Cu}$ atom, the results show that $\mathrm{Cu}$ prefers to adsorb at the bridge site between two unsaturated oxygen atoms $\left(\mathrm{O}_{2 \mathrm{c}}\right.$, see Fig. $7 \mathrm{a}$ and $\left.\mathrm{b}\right)$ with an almost linear $\mathrm{O}_{2 \mathrm{c}}-\mathrm{Cu}-\mathrm{O}_{2 \mathrm{c}}$ bond angle of $161^{\circ}$, similar to findings of previous studies. ${ }^{55-57}$ The adsorption energy $\left(E_{\text {ads }}\right)$ for one single $\mathrm{Cu}$ atom on $\mathrm{TiO}_{2}$ is $2.24 \mathrm{eV}$, which agrees well with literature. ${ }^{55-57}$ Furthermore, the two shortest $\mathrm{Cu}-\mathrm{O}$ bonds of $1.87 \AA$ are close to the $\mathrm{Cu}_{2} \mathrm{O}$ bond length $(1.85 \AA)$ but much shorter than for bulk-CuO (1.98 $)$ (Table S10 ${ }^{\dagger}$ ), and the vanishing magnetic moments and the Bader charge of +0.68 (Fig. $7 \mathrm{j}-\mathrm{l}$ ) indicate a Cu-oxidation state of +1. For small $\mathrm{Cu}_{x}$ clusters $(x=1,2,3$, and 5$)$, when 2 or $3 \mathrm{Cu}$ atoms are added to the surface, the most stable structures are still obtained for a $\mathrm{Cu}-\mathrm{O}_{2 \mathrm{c}}$ bridge sites (Fig. 7b). This indicates that $\mathrm{Cu}$ can form infinite almost linear $\mathrm{Cu}-\mathrm{O}$ chains on the $\mathrm{TiO}_{2}$ surface. Yet, the further addition of $\mathrm{Cu}$ atoms tends to destroy the symmetric chain-like 3 -atom structure and results in an irregular $3 \mathrm{D}$-like $\mathrm{Cu}_{5}$ array (Fig. 7c and d). This is more stable than the corresponding chain-like $\mathrm{Cu}_{5}$ structures and has the highest $E_{\text {ads }}$ of all considered $\mathrm{Cu}_{x}$-clusters (Table $\mathrm{S} 11 \dagger$ ). Furthermore, the charge transfer from $\mathrm{Cu}_{5}$ to $\mathrm{TiO}_{2}$ (in the DFT model each time a neutral $\mathrm{Cu}$ atom is added to the $\mathrm{TiO}_{2}$ surface) is in general smaller. As a result, $\mathrm{Cu}$ atoms of $\mathrm{Cu}_{5}$ clusters remain mainly neutral (Bader charges of -0.06 to 0.17 ), except for the $\mathrm{Cu}$ atoms directly attached on $\mathrm{TiO}_{2}$, which have still very short $\mathrm{Cu}-\mathrm{O}$ bonds or are coordinated by $2 \mathrm{O}_{2 \mathrm{c}}$ atoms (Bader charge of 0.41 to 0.66 ), indicating ionized $\mathrm{Cu}$.

For the $\mathrm{Cu}_{x} \mathrm{O}_{y}(x=5, y=0-5)$ clusters, we started from the chain-like $\mathrm{Cu}_{5}$ structure and gradually added oxygen atoms until a fully oxidized $\mathrm{Cu}$ cluster has been obtained (Fig. $7 \mathrm{~g}$ and h). We calculated the $E_{\text {ads }}$ of different metal oxide clusters on the surface and computed the cohesive energies of bulk $\mathrm{Cu}$ and CuO for comparison (Fig. 7i). For all studied clusters, the obtained $E_{\text {ads }}$ are much smaller than the cohesive energy of bulk $\mathrm{Cu}$, while showing more similar values to $\mathrm{CuO}$. The $E_{\text {ads }}$ depends only weakly on the oxygen content (or the cluster size); thus, the oxygen partial pressure and kinetic effects will determine the specific oxidation state. Furthermore, a +1 Bader charge and $0.6 \mu_{\mathrm{B}}$ magnetic moments of $\mathrm{Cu}$ atoms in the $\mathrm{Cu}_{5} \mathrm{O}_{y}$ structures, indicate that for the $\mathrm{Cu}_{5} \mathrm{O}_{5}$ cluster $\mathrm{Cu}$ is in a +2 state. However, when the number of oxygen atoms gradually decreases, the ionicity also decreases. The largest $\mathrm{Cu}_{10} \mathrm{O}_{9}$ cluster has $8 \mathrm{Cu}^{2+}$ and $2 \mathrm{Cu}^{+}$ions and 3 out of the $8 \mathrm{Cu}^{2+}$ ions have already flipped their spin indicating the preferred antiferromagnetic order of CuO. This is further shown by analyzing the dependency of the $\mathrm{Cu}$ charge state with the number of $\mathrm{O}$ neighbors (coordination number - a bond is counted when the $\mathrm{Cu}-\mathrm{O}$ distance is below $2.16 \AA$ ) shown in Fig. 7j. For simplicity, only the coordination number versus the Bader charge is shown, however, also bond angle or bond distances just below/above the cutoff criterion had some minor influence. This shows that $\mathrm{Cu}$ without or with one direct $\mathrm{O}$ neighbor is neutral, with two it is in the +1 state (Bader charge of $\sim 0.5$ ) and with 3 or 4 coordinated oxygen atoms $\mathrm{Cu}$ is in a +2 state. Hence, by increasing oxygen content, the $\mathrm{Cu}$ ionicity increases.

To check the possibility of $\mathrm{Cu}$ diffusion into the bulk, we constructed DFT models in which one $\mathrm{Cu}$ atom migrates from the surface to different positions in the subsurface. Based on the calculated $E_{\text {ads }}$ values, Fig. 7e and f shows the most stable structures of subsurface $\mathrm{Cu}$ derived from two different configurations: the single $\mathrm{Cu}$ atom and the most stable $3 \mathrm{D}$-like $\mathrm{Cu}_{5}$ cluster. As expected, when a single $\mathrm{Cu}$ atom diffuses into the subsurface there is a small energy loss $\left(E_{\text {ads }}\right.$ decreases from $2.24 \mathrm{eV}$ to $1.90 \mathrm{eV}$ ), which suggests that a single $\mathrm{Cu}$ atom is not prone to diffusion into the $\mathrm{TiO}_{2}$ lattice but is rather stable on the surface. Yet, for the larger cluster, migration of a single $\mathrm{Cu}$ atom yields virtually no energy difference (1.90 eV to $1.84 \mathrm{eV})$, which supports the possibility of $\mathrm{Cu}$ diffusion into the bulk. In both cases, the most preferable state of $\mathrm{Cu}$ incorporation in the subsurface is to be 4 -fold coordinated by $\mathrm{O}$ and present in the $\mathrm{Cu}^{+}$state, which is in line with our DRS and XPS results that indicated the reduction of the $\mathrm{Cu}^{2+}$ content. 
a)

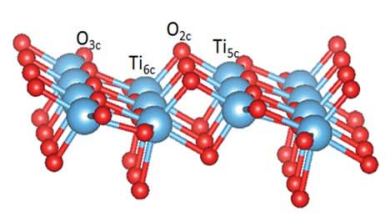

b)

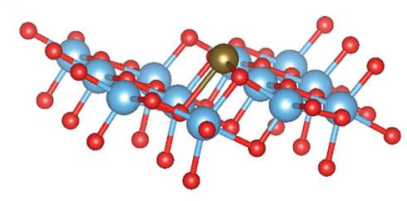

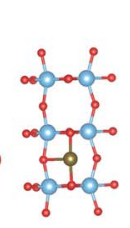
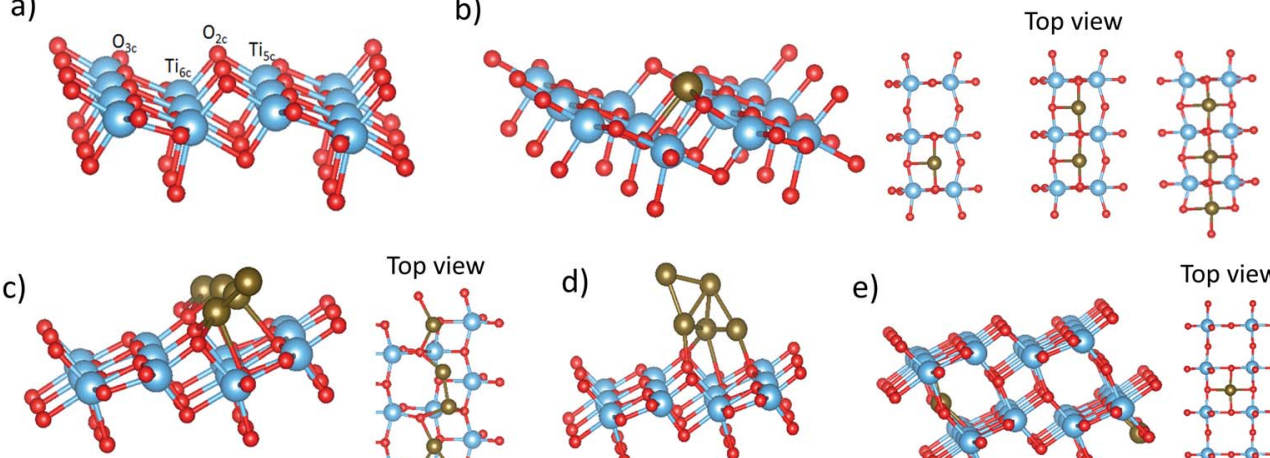

f)

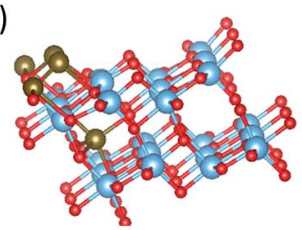

i)

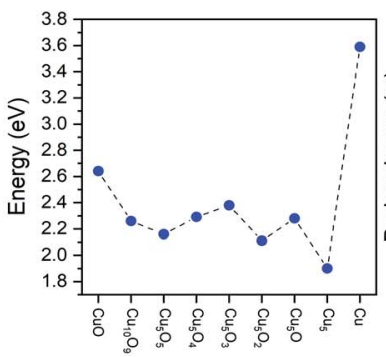

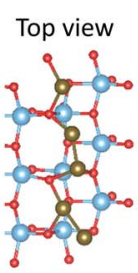

d)

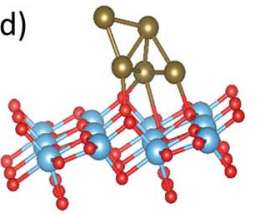

e)

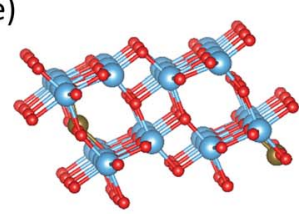

Top view

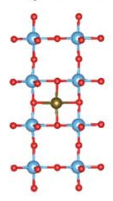

g)

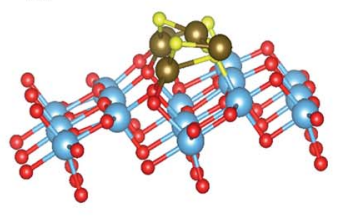

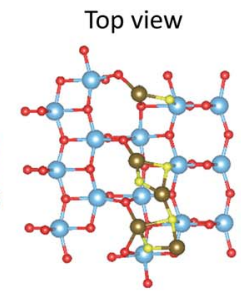

k) h)

I)

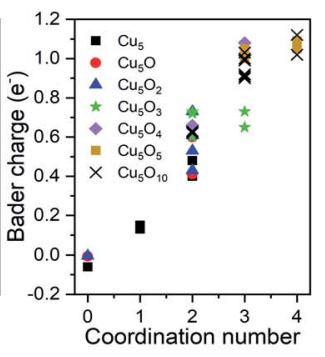

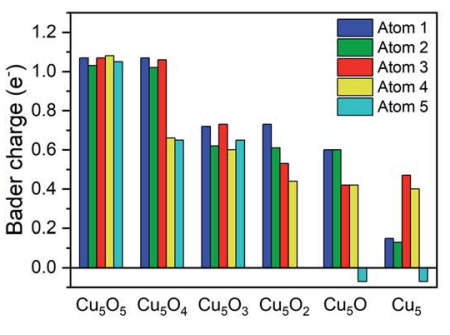

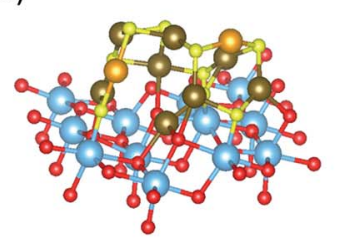

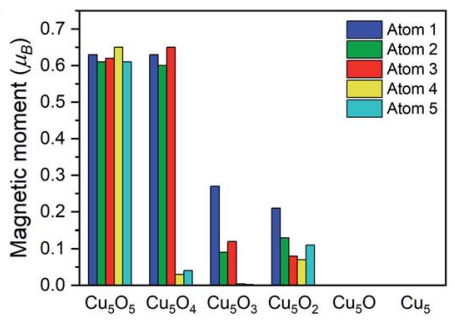

Fig. 7 (a) Side view of the anatase $\mathrm{TiO}_{2}$ (101) surface layer (in the $1 \times 3$ supercell). (b) Side and top views of adsorbed $\mathrm{Cu}_{x}(x=1,2,3)$ atoms, (c) $\mathrm{Cu}$ atoms in the chain-like structure, (d) $\mathrm{Cu}_{5} 3 \mathrm{D}$-like structure, (e) subsurface $\mathrm{Cu}$ atom, (f) one subsurface $\mathrm{Cu}$ atom in the $\mathrm{Cu}$-chain structure, (g) $\mathrm{Cu}_{5} \mathrm{O}_{5}$ cluster and (h) $\mathrm{Cu}_{10} \mathrm{O}_{9}$ cluster adsorbed on the anatase $\mathrm{TiO}_{2}$ (101) surface. (i) Adsorption energy (eV per atom) of $\mathrm{Cu}_{x} \mathrm{O}_{y} \mathrm{clusters}$ on the anatase $\mathrm{TiO}_{2}$ (101) surface, with the cohesive energy of bulk $\mathrm{CuO}$ and $\mathrm{Cu}$ as references. (j) Bader charges versus $\mathrm{Cu}$ coordination number (selected according to $\mathrm{Cu}-\mathrm{O}$ distances below $2.16 \AA$ ). Bader charges $<0.4$ correspond to $\mathrm{Cu}^{0}, 0.4-0.7$ to $\mathrm{Cu}^{+}$and $>0.7$ to $\mathrm{Cu}^{2+}$. (k) Bader charges $\left(\mathrm{e}^{-}\right)$and $(\mathrm{l})$ atomic magnetic moment (in $\left.\mu_{\mathrm{B}}\right)$ of $\mathrm{Cu}$ atoms in $\mathrm{Cu}_{5} \mathrm{O}_{y}(y=5,4,3,2,1,0)$ clusters adsorbed on the anatase $\mathrm{TiO}_{2}(101)$ surface.

Overall, the DFT results indicate that differently sized $\mathrm{Cu}$ clusters of a few atoms can indeed be stabilized on the $\mathrm{TiO}_{2}$ surface. Analysis of the $\mathrm{Cu}$ oxidation state shows that $\mathrm{Cu}^{+}$and $\mathrm{Cu}^{0}$ species are likely to form at the solid-solid interface, while $\mathrm{Cu}^{2+}$ species can only be formed as an outer cluster layer when enough oxygen is present, in line with the experimental data and the washing experiments. Furthermore, the models show that the generation of interstitial $\mathrm{Cu}^{+}$- surrounded by $4 \mathrm{O}$ atoms of $\mathrm{TiO}_{2}$ lattice - is the most stable species that can be formed via diffusion in thermally treated samples. Such $\mathrm{Cu}$ incorporation results in a minimal crystal structure change, and thus is in line with the Raman and XRD data.

$\mathrm{Cu}$ inter-band gap states. The origin of the absorption shoulder in DRS (Fig. 5a, b and 6) between 400 and $550 \mathrm{~nm}$ remains a matter of debate in literature. To uncover the nature of this shoulder, we calculated the partial density of state (PDOS) for an ideal $\mathrm{TiO}_{2}$ (101) surface and for some selected and representative configurations of adsorbed $\mathrm{Cu}, \mathrm{Cu}_{5} \mathrm{O}_{2}$ and $\mathrm{Cu}_{5} \mathrm{O}_{5}$ clusters, shown in Fig. 8.
The bare $\mathrm{TiO}_{2}$ surface (Fig. 8a) exhibits a band gap of $2.5 \mathrm{eV}$ (which is lower than the experimental value of $3.2 \mathrm{eV}$ due to the well-known DFT shortcomings), the surface Ti-d states are a bit higher in energy than in the bulk and the Ti-O covalency is reduced (see reduced Ti-surface contribution at the bottom of the valence band). Furthermore, as this $\mathrm{TiO}_{2}$ model represents an ideal surface without defects, it shows p-type conductivity in contrast to the experimental $\mathrm{TiO}_{2}$ samples. Then, when a neutral $\mathrm{Cu}$ atom is added on the $\mathrm{TiO}_{2}$-anatase (101) surface (Fig. 8b), the Fermi level moves to the conduction band (the added $\mathrm{Cu}$ is in a neutral state, thus, by adding it on the ideal$\mathrm{TiO}_{2}$ surface, $\mathrm{Cu}$ transfers negative charge to $\mathrm{TiO}_{2}$ ) and the system becomes formally metallic (n-type conductivity). Additionally, the Cu-d states show some hybridization with the O-p orbitals closest to the $\mathrm{Cu}$ atoms. This is evident in the difference of the O-PDOS of $\mathrm{O}$ atoms close/far to $\mathrm{Cu}$ atoms, from which in general a downward/upward shift of O-p states for atoms close/far to $\mathrm{Cu}$ can be observed. In any case, the main $\mathrm{Cu}$ $\mathrm{d}$ peaks are located above the VBM within the $\mathrm{TiO}_{2}$ band gap 
a)
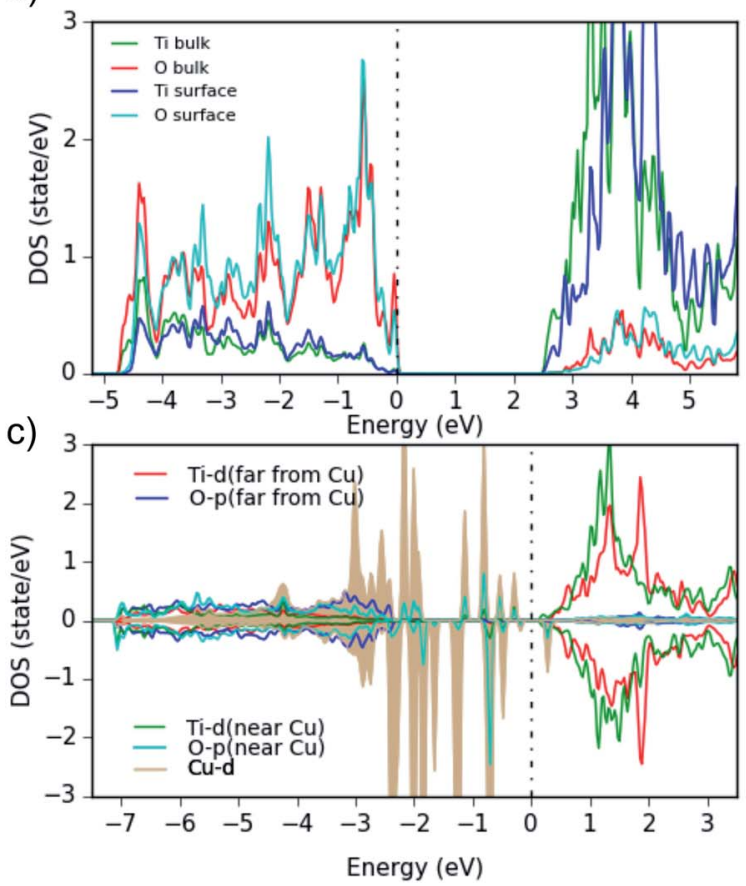

b)
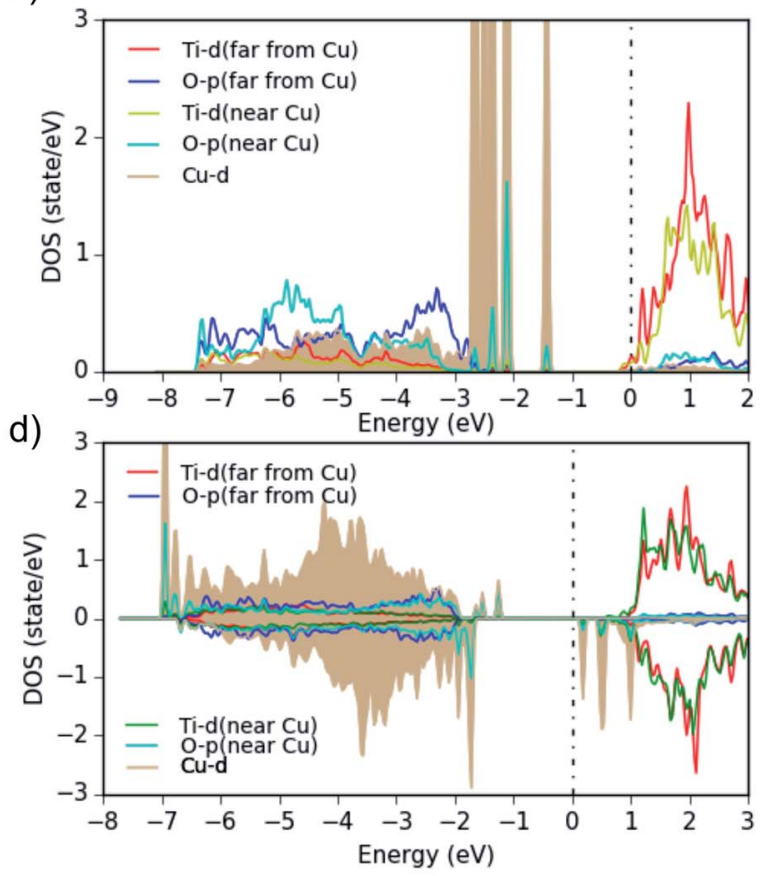

Fig. 8 Partial density of states (PDOS) for (a) bare anatase $\mathrm{TiO}_{2}$ (101) surface, showing the surface atoms and the bulk-layer states, (b) one Cu atom, (c) $\mathrm{Cu}_{5} \mathrm{O}_{2}$ and (d) $\mathrm{Cu}_{5} \mathrm{O}_{5}$ adsorbed on the surface. All Ti and O PDOS are from surface atoms only. 0 eV indicates the Fermi energy, and the plots are aligned at the $\mathrm{TiO}_{2} \mathrm{CBM}$.

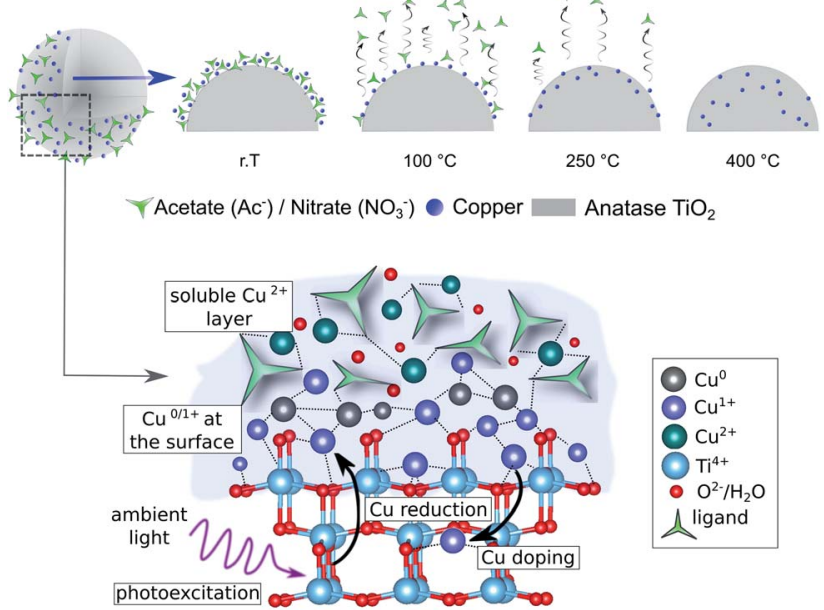

Fig. 9 Proposed mechanism of formation and evolution of $\mathrm{Cu} / \mathrm{TiO}_{2}$ photocatalysts upon thermal treatment, showing the thermally induced densification and diffusion of the $\mathrm{Cu}$ species. The bottom scheme illustrates the state of Cu-based co-catalysts during the wetimpregnation synthesis with the outer layer enriched with $\mathrm{Cu}^{2+}$, while the $\mathrm{Cu}$ species at the $\mathrm{TiO}_{2}$ surface partially turn into $\mathrm{Cu}^{+}$and $\mathrm{Cu}^{0}$ via direct electron reduction.

and are fully occupied. Larger $\mathrm{Cu}$ clusters or $\mathrm{Cu}$ diffused into the subsurface $\left(\mathrm{Cu}_{5} \mathrm{O}_{2}\right.$ and $\mathrm{Cu}_{5} \mathrm{O}_{5}$, Fig. $8 \mathrm{c}$ and d), show that the $\mathrm{Cu}$-PDOS behaves qualitatively similarly. When more oxygen is added to the $\mathrm{Cu}_{5} \mathrm{O}_{x}$ clusters, no electron transfer takes place anymore from the $\mathrm{Cu} 4 \mathrm{~s}$ (and partly $3 \mathrm{~d}$ ) to the Ti-d states at the
CBM, but to the additional $\mathrm{O}$ atoms and the Fermi level moves down to the top of the $\mathrm{Cu}$-d bands within the $\mathrm{TiO}_{2}$ gap. In addition, spin-polarization sets in, magnetic moments on (some) $\mathrm{Cu}$ atoms appear, and the Hubbard $U$ shifts fully (partially) occupied Cu-d states down (up) in energy (Fig. 8d), indicating typical $\mathrm{Cu}^{2+}$ behavior. This moves a lot of $\mathrm{Cu}-\mathrm{d}$ states down into the O-p band (e.g. in $\mathrm{Cu}_{5} \mathrm{O}_{2}$ and $\mathrm{Cu}_{5} \mathrm{O}_{4}$, Fig. 8c) and eventually in $\mathrm{Cu}_{5} \mathrm{O}_{5}$ leads to clear lower (below the O-p band) and upper (above $E_{\mathrm{F}}$ ) Hubbard bands with all $\mathrm{Cu}$ in the +2 state.

We conclude, the band gap reduction and the adsorption band between 400 and $550 \mathrm{~nm}$ of $\mathrm{Cu}\left(\mathrm{NO}_{3}\right)_{2} / \mathrm{TiO}_{2}$ and $\mathrm{Cu}(\mathrm{ac})_{2} /$ $\mathrm{TiO}_{2}$ - compared to pure $\mathrm{TiO}_{2}$ - is related in all cases to $\mathrm{Cu}-$ $\mathrm{d}$ states in the band gap of the composites. In the case of $\mathrm{Cu}_{5} \mathrm{O}_{5}$, where $\mathrm{Cu}$ is mainly in the +2 state, we can also see some $\mathrm{d}$ states above the Fermi level, which can cause d-d excitations. The transitions from the highest occupied $\mathrm{Cu}-\mathrm{d}$ states into the $\mathrm{TiO}_{2}$ conduction band may also explain the observed adsorption above $600 \mathrm{~nm}$ in Fig. 5a, b and 6.

\section{Proposed diffusion mechanism and active $\mathrm{Cu}$ state}

The combined experimental and theoretical results confirm that thermal pretreatment can indeed initiate the diffusion of $\mathrm{Cu}$ species into the $\mathrm{TiO}_{2}$ lattice, and that this process plays a key role in decreasing the photocatalytic activity towards HER. Moreover, $\mathrm{Cu}$ diffusion induces charge recombination centers, and results in lower availability of the $\mathrm{Cu}$ sites for the HER. Additionally, a mixed oxidation state of $\mathrm{Cu}^{+}, \mathrm{Cu}^{2+}$ and $\mathrm{Cu}^{0}$ is found to be in the composites at any thermal treatment; while $\mathrm{Cu}^{2+}$ is only weakly bound to the outer surface and can leach 
when in solution. Thus, we propose the following formation mechanism, which is summarized in Fig. 9: first, during the synthesis, the $\mathrm{Cu}^{2+}$ precursor species are weakly chemisorbed onto the $\mathrm{TiO}_{2}$ surface in a multilayer manner, in which the $\mathrm{Cu}$ atoms directly attached to the surface get reduced to $\mathrm{Cu}^{+}$and $\mathrm{Cu}^{0}$, facilitated by the reduction with electrons accumulated on the $\mathrm{TiO}_{2}$ surface. The low-temperature treatments of the asprepared composites $\left(\leq 150{ }^{\circ} \mathrm{C}\right)$ densify the network and enhance the electronic coupling between the $\mathrm{Cu}$ and the substrate resulting in increased HER performance (peak activity). Higher calcination temperatures $\left(>150{ }^{\circ} \mathrm{C}\right)$ induce the decomposition of precursor anions and facilitate the diffusion of $\mathrm{Cu}^{+}$species into the $\mathrm{TiO}_{2}$ lattice, which in turn introduces charge recombination centers and reduces the accessibility of the $\mathrm{Cu}$ co-catalyst at the catalyst-reactant interface leading to a strong decrease in the photocatalytic performance. ${ }^{13,58}$

\section{Conclusions}

This work sheds light on the thermally induced $\mathrm{Cu}$ diffusion into the $\mathrm{TiO}_{2}$ lattice that has a detrimental effect on photocatalytic performance. We show that calcination temperatures below $200{ }^{\circ} \mathrm{C}$ enhance the HER activity, yet treatments at higher temperatures have a surprisingly detrimental effect. Using a comprehensive set of experimental and theoretical state-ofthe-art techniques, we critically examined various possible reasons for this observation. HRTEM and XPS showed that sintering and change in the oxidation state of the $\mathrm{Cu}$ species can be excluded, as they reveal the absence of larger $\mathrm{Cu}$ clusters on the $\mathrm{TiO}_{2}$ substrate even for the high-temperature treated samples, and all samples show a mixed $\mathrm{Cu}$ oxidation state $-\mathrm{Cu}^{0}$, $\mathrm{Cu}^{+}$and $\mathrm{Cu}^{2+}$ - even for high-temperature calcined samples under air. Washing experiments show that at lower calcination temperatures $\mathrm{Cu}$ is weakly bounded and can leach off by $88.7 \%$, yet at temperatures above $250{ }^{\circ} \mathrm{C}$ the percentage drops down to $12.4 \%$ of leached $\mathrm{Cu}$. The combined assessment of XPS and XRF indicates that the drop of HER activity is not induced by leaching, but by diffusion of $\mathrm{Cu}$ into the $\mathrm{TiO}_{2}$ lattice, as XRF a bulk sensitive method, considering the nanometer-sized composites - shows a constant $\mathrm{Cu}$ concentration for all samples, while XPS - a surface-sensitive method - reveals a strong drop of the $\mathrm{Cu}$ amount on the surface. This is further supported by Raman, DRS and DFT calculations. Furthermore, the data demonstrate that a reduction of the $\mathrm{Cu}^{2+}$ precursor to mainly $\mathrm{Cu}^{+}$and partially to $\mathrm{Cu}^{0}$ takes place already after impregnation - without any further post-treatment - which indicates a photoreduction of the precursor species by $\mathrm{TiO}_{2}$ and that $\mathrm{Cu}^{+}$is stabilized as an interstitial dopant. From the results, we propose a mechanism as follows: (a) after impregnation $\mathrm{Cu}^{2+}$ is weakly bound on the substrate and get reduced by $\mathrm{TiO}_{2}$ to $\mathrm{Cu}^{+}$ and $\mathrm{Cu}^{\circ}$, (b) by increasing temperature $\mathrm{Cu}$ densifies on the substrate and (c) at temperatures $>200{ }^{\circ} \mathrm{C} \mathrm{Cu}^{+}$diffuses into the $\mathrm{TiO}_{2}$ lattice. The drop in photocatalytic performance is thus related to the diffusion of the co-catalyst species into the substrate, which generates charge recombination centers and depletes the number of co-catalyst species available on the surface for the redox reaction. This work demonstrates that mild thermal treatments of photocatalytic systems are considerably more complex than previously believed. Thus, future studies on other co-catalysts and materials need to consider the potential side effects induced by calcination.

\section{Experimental}

\section{Synthesis of the composites}

All materials used for the syntheses were obtained from commercial suppliers. As such, anatase $\mathrm{TiO}_{2}$ from SigmaAldrich, $\mathrm{Cu}(\mathrm{ac})_{2}$ (98\% pure) and $\mathrm{Cu}\left(\mathrm{NO}_{3}\right)_{2}$ from Sigma Aldrich (98\% pure). The used solvent for the syntheses was absolute ethanol (from Chem-Lab NV) and for photocatalytic experiments deionized water and HPLC-gradient grade methanol (from VWR). The composites were synthesized by a wet impregnation method with a post-synthesis thermal treatment. The general synthesis procedure used for all samples included (a) suspending the $\mathrm{TiO}_{2}$ powder ( $400 \mathrm{mg}, 5 \mathrm{mmol}$ ) in ethanol (20 $\mathrm{mL}$ ); (b) stirring the suspension for 5 minutes; (c) adding the corresponding precursor salt: $\mathrm{Cu}(\mathrm{ac})_{2} / \mathrm{Cu}\left(\mathrm{NO}_{3}\right)_{2}(0.05 \mathrm{mmol})$ and stirring for another $5 \mathrm{~min}$, (d) subjecting the resulting suspension to sonication to assist salt dissolution and homogenization of the suspension components for 15 minutes, (e) the resulting mixture was left stirring for 30 minutes; and (f) the ethanol was extracted under vacuum. The remaining powder was then ground. Afterwards, the samples were heat-treated at the corresponding temperature with a heating ramp of $2 \mathrm{~h}$ until reaching the desired temperature, in ambient air.

\section{Characterisation methods}

Transmission electron microscopy (TEM) images were obtained using FEI TECNAI F20 transmission electron microscope equipped with a field emission gun in bright field mode using $200 \mathrm{kV}$ acceleration voltage. The sample was prepared from an ethanol suspension, using a copper holey carbon-coated grid (Plano, 200 mesh). X-ray diffraction (XRD) was performed using an XPERT III: PANalytical XPert Pro MPD $(\theta-\theta$ Diffractometer $)$ for the in situ experiments and an XPERT II: PANalytical XPert Pro MPD ( $\theta-\theta$ Diffractometer) for the ex situ experiments. The sample was placed on a sample holder and irradiated with a $\mathrm{Cu}$ X-ray source $(8.04 \mathrm{keV}, 1.5406 \AA$ ). The signal was acquired with Bragg-Brentano $\theta / \theta$-diffractometer geometry ranging from $5^{\circ}$ to $80^{\circ}$ degrees. The detector system was a semiconductor $\mathrm{X}^{\prime}$ Celerator $\left(2.1^{\circ}\right)$ detector. The in situ experiment was performed under air flow and temperatures ranging from $25{ }^{\circ} \mathrm{C}$ to $800{ }^{\circ} \mathrm{C}$. The $e x$ situ experiments were performed with a Si NIST certified standard reference material (SRM 640d) as an internal standard. The internal standard was required in order to detect the crystal parameter changes of the samples. Refinements were done according to the instruction provided by the standard. The thermogravimetric (TGA) measurements were carried out on a PerkinElmer Thermogravimetric Analyser TGA 8000. The samples were placed into an $\mathrm{Al}_{2} \mathrm{O}_{3}$ crucible and heated with a dynamic method at a heating rate of $5{ }^{\circ} \mathrm{C} \mathrm{min}{ }^{-1}$ under air from $25{ }^{\circ} \mathrm{C}$ to $800{ }^{\circ} \mathrm{C}$. The chemical composition of the samples was obtained with two different X-ray photoelectron spectroscopy 
(XPS) machines. The Auger spectra were determined using a Thermo Fisher Microlab 310/350-spectrometer equipped with a twin anode $\mathrm{Al} / \mathrm{Mg}-\mathrm{K} \alpha \mathrm{X}$-ray source (XR3) and a hemispherical analyzer. Pass energies of $70 \mathrm{eV}$ and $20 \mathrm{eV}$, as well as energy resolutions of $1 \mathrm{eV}$ and $100 \mathrm{meV}$, were used for survey and detail spectra respectively (excitation energy: $1486.6 \mathrm{eV} / 1253.6 \mathrm{eV}$, beam power: $100 \mathrm{~W}$, angle: $60^{\circ}$ to sample surface normal, base pressure: $2 \times 10^{-8}$ mbar, pressure during measurements: $3 \times$ $\left.10^{-8} \mathrm{mbar}\right)$. All measurements were carried out with the sample in normal emission angle with respect to the analyzer. The samples were mounted onto the sample holder using doublesided carbon tape. The XPS spectra were acquired using an Axis Ultra DLD instrument from Kratos Analytical (UK) with the base pressure during spectra acquisition better than $1.1 \times 10^{-9}$ torr $\left(1.5 \times 10^{-7} \mathrm{~Pa}\right)$, achieved by a combination of turbomolecular and ion pumps. Monochromatic Al-K $\alpha$ radiation $(h \nu=$ $1486.6 \mathrm{eV}$ ) is employed with the anode power set to $150 \mathrm{~W}$. All spectra are collected at normal emission angle. Ultraviolet photoemission spectroscopy (UPS) experiment was carried out in home-built MOSES spectrometer under a base pressure of $5 \times$ $10^{-10}$ mbar equipped with a monochromatic He-I radiation source $(h \nu=21.22 \mathrm{eV})$. All spectra were collected at normal emission and at room temperature. The total resolution of UPS is about $0.1 \mathrm{eV}$ estimated from the width of the Fermi edge of a sputter-cleaned Au film. The signal was calibrated by using the Fermi edge of this sputtered Au. To extract sample work function, a bias of $-50 \mathrm{~V}$ was applied to the sample during the UPS measurement. Data analysis was done using the CasaXPS Version 2.3.19PR1.0 software package employing Shirley/Shirley Tougaard backgrounds and Scofield sensitivity factors. ${ }^{\mathbf{5 9 , 6 0}}$ Curve fits using combined Gaussian-Lorentzian peak shapes (GL(30)) were used to discern the components of detail spectra if not stated otherwise. For the peak analysis a charge correction was applied to the adventitious carbon peak (C-C peak) shifting to $284.8 \mathrm{eV}$ binding energy (BE) due to the absence of a clear Fermi edge and for comparison to literature values, while for the VBM, where the indium foil was used, a charge correction was done to the Fermi level. All content values shown are in units of a relative atomic percent (at\%), where the detection limit in survey measurements usually lies around 0.1-0.5 at\%, depending on the element. The accuracy of XPS measurements is around 10$20 \%$ of the values shown. Assignment of different components was primarily done using ref. 61 and 62 . For the attenuated total reflection Fourier-transform infrared spectroscopy (ATR-FTIR) measurements a PerkinElmer FTIR Spectral UATR-TWO with a spectrum two Universal ATR (Single Reflection Diamond) accessory was used. Raman measurement was conducted with LabRAM HR800 (HORIBA Co. Ltd). Ne:YAG diode was used as $532 \mathrm{~nm}$ laser source and the characteristic Raman peak of Si at $520.8 \mathrm{~cm}^{-1}$ was used as the calibration peak. The laser intensity was kept at $5 \mathrm{~mW}$. The obtained signal intensity was normalized to the anatase sample to avoid measuring artifacts. The X-ray Fluorescence Spectroscopy (XRF) chemical quantification analysis was performed with an Atomika 8030C X-ray fluorescence analyzer in total reflection geometry (XRF) with a molybdenum $\mathrm{X}$-ray source (monochromatized $\mathrm{K} \alpha$-line). The excitation conditions were $50 \mathrm{kV}$ and $47 \mathrm{~mA}$ for $100 \mathrm{~s}$ irradiation time and an energy-dispersive $\mathrm{Si}(\mathrm{Li})$-detector was employed. For the sample preparation, all reflectors were washed thoroughly and measured to account for true blanks. $1 \mathrm{mg}$ of the solid nanopowder was loaded on the clean reflectors and sealed with 5 $\mu \mathrm{L}$ of a $1 \%$ PVA solution to avoid contamination of the detector. After drying for $5 \mathrm{~min}$ on a hot plate and cooling, the reflectors with the loaded samples were measured. For the data evaluation, Ti was set as a matrix with $100 \%$ (wt\%) and relative amounts of $\mathrm{Cu}$ were acquired (wt\%). The Diffuse Reflectance Ultra-violet Spectroscopy (DRS or DR-UV-vis) a Jasco V-670 UV-Vis photo spectrometer has been used to measure diffusive reflectance spectra. The optical band gap was determined with the Tauc plots and with the exponent value, $n=1 / 2$ for direct allowed transition.

\section{Photocatalytic experiments}

Hydrogen evolution experiments were performed using a top irradiation flow-reactor (total volume of $100 \mathrm{~mL}$ ) equipped with an LED light source with incident light intensity of $0.488 \mathrm{~W}$ centred at $365 \mathrm{~nm} \pm 15 \mathrm{~nm}\left(192 \mathrm{~mW} \mathrm{~cm}^{-2}\right.$, Thorlabs SOLIS). In a single experiment, the powdered photocatalyst $(10 \mathrm{mg})$ was dispersed in $40 \mathrm{~mL} 1: 1 \mathrm{vol} \% \mathrm{MeOH}$-water solution. During the experiment, the reactor was continuously purged with argon (flow rate of $30 \mathrm{~mL} \mathrm{~min}^{-1}$, controlled with a mass flow controller from MCC-Instruments) to deliver the gaseous products to the online gas analyzer (X-Stream ${ }^{\circledR}$, Emerson Process Management) equipped with a thermal conductivity detector (TCD) for $\mathrm{H}_{2}$ quantification with an unmatchable sensitivity (down to ppm level) and time-resolution (one data point per second, see Fig. $\mathrm{S} 1 \dagger$ ). A typical $\mathrm{H}_{2}$ evolution profile obtained with our flow reactor includes an "induction" period (increasing $\mathrm{H}_{2}$ evolution rate during the first minutes) that is purely related to the fact the $\mathrm{H}_{2}$ gas first needs to fill the dead volume (e.g., reactor volume, tubing volume) to reach the detector. The temperature of the reactor was kept constant through a water-cooling system (Lauda).

\section{Computational methods}

To understand the experimental observations regarding the influence of the copper oxidation state on $\mathrm{H}_{2}$ production activity, spin-polarized DFT calculations of the model $\mathrm{Cu}_{x} \mathrm{O}_{y}$ clusters $(x=1,2,3,5,10$ and $y=0,1, \ldots, 5,9)$ adsorbed on the anatase $\mathrm{TiO}_{2}$ (101) surface were performed using the fullpotential augmented plane wave plus local orbitals method as implemented in the WIEN2k code. ${ }^{63-65}$ The $\mathrm{TiO}_{2}$-anatase (101) surface was chosen as it is the most abundant and stable anatase surface. ${ }^{\mathbf{6 6 , 6 7}}$ We employed the PBEsol exchange-correlation functional, which is a generalized gradient approximation (GGA) and yields lattice parameters of bulk anatase $\mathrm{TiO}_{2}$, $a=b=3.77 \AA$ and $c=9.54 \AA$ which are in good agreement with experimental data. ${ }^{68}$ In order to treat the correlated $3 \mathrm{~d}$ electrons a Hubbard $U$ correction was used. ${ }^{69}$ A value of $U_{\text {eff }}=U-J=5 \mathrm{eV}$

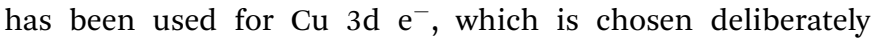
smaller than what is typically used in strongly correlated $\mathrm{Cu}$ oxides, since in our case also less ionic (neutral) clusters were investigated and the correlation may not be always so strong. 
The (101) surface was modeled by a symmetric slab with a thickness of three layers of $\mathrm{TiO}_{2}$ (Fig. S20 $\dagger$ ), where only one layer is shown for better visibility and a vacuum region of $16 \AA$ between the slabs. In order to reduce the interactions between the adsorbed clusters in neighboring cells, a $1 \times 3$ supercell was used for all surfaces with adsorbed clusters. Moreover, such a supercell is also helpful to release the interfacial strain energy and find more stable configurations. A $2 \times 2 \times 1 \Gamma$-centered mesh of $k$-points was used during relaxation (a $5 \times 4 \times 1$ mesh for the final results) and a basis-set size corresponding to $R_{\mathrm{MT}}^{\min } K_{\max }=7$ was used for the $\mathrm{Cu}_{x}$ models (atomic sphere radii $R_{\mathrm{MT}}$ of $\mathrm{Ti}=1.7, \mathrm{Cu}=1.65, \mathrm{O}=1.4 \mathrm{bohr}$ ), while the $\mathrm{Cu}_{x} \mathrm{O}_{y}$ models used $R_{\mathrm{MT}}^{\min } K_{\max }=5.45$, because the O spheres had to be reduced to 1.09 bohr. All surface models were relaxed until the residual forces were below $1 \mathrm{mRy} \mathrm{bohr}^{-1}$. Consistent $R_{\mathrm{MT}}$ and $R_{\mathrm{MT}}^{\min } K_{\max }$ values were used for calculating the adsorption energy per atom $E_{\text {ads }}$ of clusters on the anatase surface, which is defined as

$$
\begin{aligned}
E_{\mathrm{ads}}= & \frac{1}{x+y}\left[E\left(\mathrm{TiO}_{2}(101)\right)+x E(\mathrm{Cu})+y \frac{1}{2} E\left(\mathrm{O}_{2}\right)\right. \\
& \left.-E\left(\mathrm{Cu}_{x} \mathrm{O}_{y} / \mathrm{TiO}_{2}(101)\right)\right]
\end{aligned}
$$

where $E(\mathrm{Cu})$ and $E\left(\mathrm{O}_{2}\right)$ are the total energies of the free $\mathrm{Cu}$ atom and the $\mathrm{O}_{2}$ molecule in the gas phase, $E\left(\mathrm{TiO}_{2}(101)\right)$ is for the bare $\mathrm{TiO}_{2}(101)$ surface, and $E\left(\mathrm{Cu}_{x} \mathrm{O}_{y} / \mathrm{TiO}_{2}(101)\right)$ is the total energy of anatase with the surface-attached cluster. To calculate the oxidation state and the magnetic moment of each atom, we used Bader's method, which uses the electron density to calculate the gradient vector field and the atomic basins by searching for surfaces of zero flux. ${ }^{\mathbf{7 0 , 7 1}} \mathrm{An}$ integral of the electron (spin) density enclosed within these basins defines the total electronic charge (magnetic moment) of an atom. To provide reference values for oxidation states, calculations for bulk $\mathrm{Cu}$, $\mathrm{Cu}_{2} \mathrm{O}$, and antiferromagnetic $\mathrm{CuO}$ were also done.

\section{Author contributions}

Jasmin S. Schubert: methodology, validation, formal analysis, investigation, writing - original draft, data curation, visualization. Leila Kalantari: investigation, formal analysis, writing review \& editing, data curation, software, visualization. Andreas Lechner: investigation, formal analysis, visualization. Ariane Giesriegl: investigation. Sreejith P. Nandan: investigation. Pablo Alaya: investigation. Shun Kashiwaya: investigation, writing review \& editing. Markus Sauer: writing - review \& editing, resources. Annette Foelske: writing - review \& editing, resources. Johanna Rosen: writing - review \& editing. Peter Blaha: supervision, writing - review \& editing. Alexey Cherevan: conceptualization, methodology, supervision, project administration, writing - review \& editing. Dominik Eder: conceptualization, supervision, writing - review \& editing, project administration, funding acquisition, resources.

\section{Conflicts of interest}

There are no conflicts to declare.

\section{Acknowledgements}

The authors would like to acknowledge the facilities of the Technische Universität Wien (TU Wien) for technical support and fruitful discussions: X-Ray Center (XRC) and especially Werner Artner and Klaudia Hradil; Analytical Instrumentation Center (AIC), Electron Microscopy Center (USTEM) and TU Wien Atominstitute, Tushar Gupta for supplementary TEM measurements, Jia Wang for the Raman measurements, Grzegorz Greczynski for the XPS measurements and Xianjie Liu for the UPS measurements. We further thank the SSF Foundation (EM16-0004), Austrian Science Fund (FWF, Project number P32801) and acknowledge support by the TU-D doctoral college (TU Wien). The authors acknowledge the TU Wien Bibliothek for financial support through its Open Access Funding Program.

\section{References}

1 T. Jafari, E. Moharreri, A. S. Amin, R. Miao, W. Song and S. L. Suib, Molecules, 2016, 21, 900.

2 A. Kudo and Y. Miseki, Chem. Soc. Rev., 2008, 38, 253-278.

3 X. Li, J. Yu, J. Low, Y. Fang, J. Xiao and X. Chen, J. Mater. Chem. A, 2015, 3, 2485-2534.

4 I. Roger, M. A. Shipman and M. D. Symes, Nat. Rev. Chem., 2017, 1, 0003.

5 B. M. Hunter, H. B. Gray and A. M. Müller, Chem. Rev., 2016, 116, 14120-14136.

6 S. Bai, W. Jiang, Z. Li and Y. Xiong, ChemNanoMat, 2015, 1, 223-239.

7 M.-K. Jeon, J.-W. Park and M. Kang, J. Ind. Eng. Chem., 2007, 1, 84-91.

8 N.-L. Wu and M.-S. Lee, Int. J. Hydrogen Energy, 2004, 29, 1601-1605.

9 A. J. J. Lennox, P. Bartels, M.-M. Pohl, H. Junge and M. Beller, J. Catal., 2016, 340, 177-183.

10 M. Jung, J. Scott, Y. H. Ng, Y. Jiang and R. Amal, Int. J. Hydrogen Energy, 2014, 39, 12499-12506.

11 Y. Wu, G. Lu and S. Li, Catal. Lett., 2009, 133, 97.

12 H.-J. Choi and M. Kang, Int. J. Hydrogen Energy, 2007, 32, 3841-3848.

13 M. Nolan, A. Iwaszuk, A. K. Lucid, J. J. Carey and M. Fronzi, Adv. Mater., 2016, 28, 5425-5446.

14 L. Zhang, Q. Zheng, Y. Xie, Z. Lan, O. V. Prezhdo, W. A. Saidi and J. Zhao, Nano Lett., 2018, 8.

15 Q. Hu, J. Huang, G. Li, Y. Jiang, H. Lan, W. Guo and Y. Cao, Appl. Surf. Sci., 2016, 382, 170-177.

16 M. Jung, J. N. Hart, J. Scott, Y. H. Ng, Y. Jiang and R. Amal, Appl. Catal., A, 2016, 521, 190-201.

17 J. Yu, Y. Hai and M. Jaroniec, J. Colloid Interface Sci., 2011, 357, 223-228.

18 J. Bandara, C. P. K. Udawatta and C. S. K. Rajapakse, Photochem. Photobiol. Sci., 2005, 4, 857-861.

19 T. Akita, P. Lu, S. Ichikawa, K. Tanaka and M. Haruta, Surf. Interface Anal., 2001, 31, 73-78.

20 N. Waiskopf, Y. Ben-Shahar and U. Banin, Adv. Mater., 2018, 30, 1706697. 
21 F. A. L. Laskowski, S. Z. Oener, M. R. Nellist, A. M. Gordon, D. C. Bain, J. L. Fehrs and S. W. Boettcher, Nat. Mater., 2020, 19, 69-76.

22 A. El Mragui, Y. Logvina, L. Pinto da Silva, O. Zegaoui and J. C. G. Esteves da Silva, Materials, 2019, 12(23), 3874.

23 T. Ohsaka, F. Izumi and Y. Fujiki, J. Raman Spectrosc., 1978, 7, 321-324.

24 W. Li, L. Fang, G. Qin, H. Ruan, H. Zhang, C. Kong, L. Ye, P. Zhang and F. Wu, J. Appl. Phys., 2015, 117, 145301.

25 A. Chanda, K. Rout, M. Vasundhara, S. R. Joshi and J. Singh, RSC Adv., 2018, 8, 10939-10947.

26 J. I. Garza-Arévalo, I. García-Montes, M. H. Reyes, J. L. Guzmán-Mar, V. Rodríguez-González and L. H. Reyes, Mater. Res. Bull., 2016, 73, 145-152.

27 A. A. Kashale, A. S. Rasal, G. P. Kamble, V. H. Ingole, P. K. Dwivedi, S. J. Rajoba, L. D. Jadhav, Y.-C. Ling, J.-Y. Chang and A. V. Ghule, Composites, Part B, 2019, 167, 44-50.

28 M. R. Joya, K. M. Fonseca and J. Barba-Ortega, AIP Conf. Proc., 2014, 1627, 42-45.

29 P. Colomban and A. Slodczyk, Acta Phys. Pol., A, 2009, 116, 7. 30 J. Halim, M. R. Lukatskaya, K. M. Cook, J. Lu, C. R. Smith, L.-A․ Näslund, S. J. May, L. Hultman, Y. Gogotsi, P. Eklund and M. W. Barsoum, Chem. Mater., 2014, 26, 2374-2381.

31 A. M. Alotaibi, B. A. D. Williamson, S. Sathasivam, A. Kafizas, M. Alqahtani, C. Sotelo-Vazquez, J. Buckeridge, J. Wu, S. P. Nair, D. O. Scanlon and I. P. Parkin, ACS Appl. Mater. Interfaces, 2020, 12, 15348-15361.

32 M. Y. Mihaylov, V. R. Zdravkova, E. Z. Ivanova, H. A. Aleksandrov, P. St. Petkov, G. N. Vayssilov and K. I. Hadjiivanov, J. Catal., 2021, 394, 245-258.

33 V. Krylova and M. Andrulevičius, Int. J. Photoenergy, 2009, 2009, e304308.

34 M. C. Biesinger, B. P. Payne, A. P. Grosvenor, L. W. M. Lau, A. R. Gerson, R. St and C. Smart, Appl. Surf. Sci., 2011, 257, 2717-2730.

35 M. C. Biesinger, Surf. Interface Anal., 2017, 49, 1325-1334.

36 J. Y. Park, Y. C. Kang, K. A. Lim and R. D. Ramsier, Bull. Korean Chem. Soc., 2011, 32, 3395-3399.

37 L. P. Bevy, Focus on Catalysis Research, Nova Publishers, 2006.

38 X. Qiu, M. Miyauchi, K. Sunada, M. Minoshima, M. Liu, Y. Lu, D. Li, Y. Shimodaira, Y. Hosogi, Y. Kuroda and K. Hashimoto, ACS Nano, 2012, 6, 1609-1618.

39 S. Pande, M. G. Weir, B. A. Zaccheo and R. M. Crooks, New J. Chem., 2011, 35, 2054-2060.

40 A. Dikhtiarenko, P. Villanueva-Delgado, R. Valiente, J. R. García and J. Gimeno, Polymers, 2016, 8(2), 48.

41 B. Viswanathan, Catalysis: Principles and Applications, CRC Press, 2002.

42 H. Irie, K. Kamiya, T. Shibanuma, S. Miura, D. A. Tryk, T. Yokoyama and K. Hashimoto, J. Phys. Chem. C, 2009, 113, 10761-10766.

43 H. Irie, S. Miura, K. Kamiya and K. Hashimoto, Chem. Phys. Lett., 2008, 457, 202-205.

44 K. Wang, L. Yang, W. Zhao, L. Cao, Z. Sun and F. Zhang, Green Chem., 2017, 19, 1949-1957.
45 P. Makuła, M. Pacia and W. Macyk, J. Phys. Chem. Lett., 2018, 9, 6814-6817.

46 I. Ganesh, P. P. Kumar, I. Annapoorna, J. M. Sumliner, M. Ramakrishna, N. Y. Hebalkar, G. Padmanabham and G. Sundararajan, Appl. Surf. Sci., 2014, 293, 229-247.

47 S. Mathew, P. Ganguly, S. Rhatigan, V. Kumaravel, C. Byrne, S. J. Hinder, J. Bartlett, M. Nolan and S. C. Pillai, Appl. Sci., 2018, 8, 2067.

48 A. Kahn, Mater. Horiz., 2015, 3, 7-10.

49 S. Kashiwaya, J. Morasch, V. Streibel, T. Toupance, W. Jaegermann and A. Klein, Surfaces, 2018, 1, 73-89.

50 S. Moser, L. Moreschini, J. Jaćimović, O. S. Barišić, H. Berger, A. Magrez, Y. J. Chang, K. S. Kim, A. Bostwick, E. Rotenberg, L. Forró and M. Grioni, Phys. Rev. Lett., 2013, 110, 196403.

51 K. Ozawa, M. Emori, S. Yamamoto, R. Yukawa, S. Yamamoto, R. Hobara, K. Fujikawa, H. Sakama and I. Matsuda, J. Phys. Chem. Lett., 2014, 5, 1953-1957.

52 S. Selcuk and A. Selloni, Nat. Mater., 2016, 15, 1107-1112.

53 U. Diebold, Surf. Sci. Rep., 2003, 48, 53-229.

54 D. Spanu, A. Minguzzi, S. Recchia, F. Shahvardanfard, O. Tomanec, R. Zboril, P. Schmuki, P. Ghigna and M. Altomare, ACS Catal., 2020, 10, 8293-8302.

55 S. K. Iyemperumal, T. G. Fenton, S. L. Gillingham, A. D. Carl, R. L. Grimm, G. Li and N. A. Deskins, J. Chem. Phys., 2019, 151, 054702.

56 A. Alghannam, C. L. Muhich and C. B. Musgrave, Phys. Chem. Chem. Phys., 2017, 19, 4541-4552.

57 N. Seriani, C. Pinilla and Y. Crespo, J. Phys. Chem. C, 2015, 119, 6696-6702.

58 Z. Lin, D. Han and S. Li, J. Therm. Anal. Calorim., 2012, 107, 471-475.

59 S. Tougaard, Surf. Interface Anal., 1997, 25, 137-154.

60 D. A. Shirley, Phys. Rev. B: Solid State, 1972, 5, 4709-4714.

61 C. D. Wagner, A. V. Naumkin, A. Kraut-Vass, J. W. Allison, C. J. Powell and J. R. Rumble, NIST standard reference database, 2003, vol. 20, ch. 3, pp. 251-252.

62 G. Beamson and D. Briggs, Anal. Chem., 1992, 64, 1729-1736. 63 P. Blaha, K. Schwarz, G. K. H. Madsen, D. Kvasnicka, J. Luitz, R. Laskowsk, F. Tran, L. Marks and L. Marks, WIEN2k: An Augmented Plane Wave Plus Local Orbitals Program for Calculating Crystal Properties, Techn. Universitat, 2019.

64 D. J. Singh and L. Nordstrom, Planewaves, Pseudopotentials, and the LAPW Method, Springer US, 2nd edn, 2006.

65 P. Blaha, K. Schwarz, F. Tran, R. Laskowski, G. K. H. Madsen and L. D. Marks, J. Chem. Phys., 2020, 152, 074101.

66 M. Lazzeri, A. Vittadini and A. Selloni, Phys. Rev. B: Condens. Matter Mater. Phys., 2001, 63, 155409.

67 M. Lazzeri, A. Vittadini and A. Selloni, Phys. Rev. B: Condens. Matter Mater. Phys., 2002, 65, 119901.

68 J. P. Perdew, A. Ruzsinszky, G. I. Csonka, O. A. Vydrov, G. E. Scuseria, L. A. Constantin, X. Zhou and K. Burke, Phys. Rev. Lett., 2008, 100, 136406.

69 V. I. Anisimov, J. Zaanen and O. K. Andersen, Phys. Rev. B: Condens. Matter Mater. Phys., 1991, 44, 943-954.

70 R. F. W. Bader, Chem. Rev., 1991, 91, 893-928.

71 R. F. W. Bader, Atoms in Molecules: A Quantum Theory, Oxford University Press, Oxford, New York, 1994. 